\title{
A Numerical Investigation of the Potential Effects of Aerosol-Induced Warming and Updraft Width and Slope on Updraft Intensity in Deep Convective Clouds
}

\author{
ZACHARY LEBO \\ Department of Atmospheric Science, University of Wyoming, Laramie, Wyoming
}

(Manuscript received 21 December 2016, in final form 31 October 2017)

\begin{abstract}
The effects of aerosol perturbations on deep convective clouds have received considerable attention in the recent literature, especially from a modeling perspective. The published responses in precipitation amount and updraft strength vary in both sign and magnitude and may be the result of different models and parameterizations. Here, a simple numerical framework is employed to determine the potential effects of warming both below the freezing level (warm invigoration) and above the freezing level (mixed-phase invigoration) due to increased aerosol loading. The role of updraft width and slope in the same framework is also examined, highlighting the relative importance of each factor on the resulting updraft strength. The results show that the potential effects of warm invigoration are 2-3 times larger than for mixed-phase invigoration. However, a relatively small response in updraft velocity to warming is found, especially in comparison with the predicted changes in updraft velocity due to small differences in system slope and width, with $87.7 \%$ and $96.4 \%$ of the subadiabatic and adiabatic realizations, respectively, showing changes in updraft velocity of less than $15 \%$ for warmings of no more than $2^{\circ} \mathrm{C}$. This result suggests that observations of the aerosol effect will be largely muddled by the natural variability of convective updraft width and slope (which are related to environmental wind shear).
\end{abstract}

\section{Introduction}

Investigations aimed at understanding and quantifying the impacts of changes in aerosol loading on deep convective clouds have become more numerous in the literature over the last decade. Attempts have been made to examine the effects using cloud-resolving and thermodynamic model simulations (e.g., Khain et al. 2004; Grabowski 2006; Van den Heever et al. 2006; Tao et al. 2007; Lee et al. 2008; Rosenfeld et al. 2008; Fan et al. 2009; Ekman et al. 2011; Seifert et al. 2012; Seigel et al. 2013; Lebo and Morrison 2014) and observations (e.g., Rosenfeld and Woodley 2000; Berg et al. 2008; Koren et al. 2008, 2010; Li et al. 2011; Yuan et al. 2011; Heiblum et al. 2012). These prior works have provided generally inconsistent results regarding the influence of changes in aerosol loading on precipitation and updraft velocities. Many modeling studies have found the effect of increased aerosols on updraft vigor to be small (e.g., Van den Heever et al. 2006; Fan et al. 2009; Lebo and Morrison 2014), especially in contrast to some observational studies that show large effects (e.g., Li et al. 2011);

Corresponding author: Zachary Lebo, zlebo@uwyo.edu it is likely that the differences between studies could be a function of different environments, numerical parameterizations, model domain configurations, etc.

Although there are several pathways by which a change in aerosol loading can affect precipitation and updraft velocities in deep convective clouds, the "invigoration" hypothesis has received the most attention in the literature and has been argued to have a relatively large impact on convective storm strength (Rosenfeld et al. 2008; referred to hereinafter as mixed-phase invigoration). According to this hypothesis and based on the thermodynamic parcel simulations of Rosenfeld et al. (2008), increased aerosol loading leads to smaller but more numerous cloud drops compared with a pristine environment. These smaller drops have lower collection efficiencies, which makes them less likely to coalesce to form raindrops that are capable of falling to the surface instead of following the air motion. Thus, the small cloud drops are lofted to levels where they freeze and subsequently grow via deposition and/or riming, both acting as additional sources of released latent energy and increased temperatures aloft. This increase in temperature directly increases the buoyancy of a rising parcel, driving stronger updrafts. 
There are several key assumptions in Rosenfeld et al. (2008) that may directly affect the quantitative response in updraft velocity due to aerosol effects. First, all condensate is retained within a rising parcel until reaching the $-4^{\circ} \mathrm{C}$ level, where the liquid freezes and is precipitated out of the parcel. As the parcel continues to rise, all condensate (regardless of phase and expected hydrometeor size) is offloaded from the parcel; that is, there is no hydrometeor loading above the freezing level. Including the loading of hydrometeors aloft would suppress the mixed-phase invigoration effect. Second, freezing is often not initiated in clouds at temperatures near $0^{\circ} \mathrm{C}$, typically occurring at much lower temperatures (e.g., Boudala et al. 2004; Kanitz et al. 2011; Murray et al. 2012); thus, shifting the phase change upward should further suppress the invigoration effect. Third, changes in updraft velocity are derived from changes in buoyancy, neglecting the effects of perturbation pressure gradients, which should also suppress the mixed-phase invigoration effect. Fourth, the effects of subadiabatic ascent were not considered, which could result in a larger invigoration effect. Fifth, a single sounding was chosen, meaning that the results may not be applicable to all environments conducive to convection. Last, the aerosol-induced effects are only considered in the sense of changes in the mixed-phase region of a deep convective cloud; however, recent studies have suggested that changes in the warm sector (i.e., liquidonly microphysics) could be as important (if not more) on the resulting updraft velocity (e.g., Sheffield et al. 2015; Lebo 2014). This is called "warm invigoration" and arises from the fundamental relationship between growth via condensation and drop size. Simply put, two parcels of air with the same liquid water content but one having smaller more numerous drops (polluted scenario) compared to the other (clean scenario) will result in an increase in the bulk condensation rate, providing a positive buoyancy contribution. A primary objective of this work is to address some of these potential shortcomings, primarily the last five, while still using a relatively simple modeling framework, thus allowing for the exploration of a larger portion of the relevant parameter space.

Although attempts have been made to collect observations of the aerosol impacts on deep convective clouds, especially using spaceborne measurement platforms (e.g., Koren et al. 2010; Heiblum et al. 2012) and ground-based measurements (e.g., Li et al. 2011), it is unclear to what extent the observed differences in deep convective cloud characteristics (commonly analyzed in terms of cloud-top height changes) are due to aerosol perturbations or differences in environmental characteristics. Moreover, these works simply document correlations without providing evidence of causality or elucidating the dominant physical processes at play. Observations of these systems present an additional problem in that no two systems are alike. Therefore, observing aerosol effects on deep convective cloud systems is convoluted by the notion that different aerosol loadings arise under different environmental conditions [different relative humidity, shear, convective available potential energy (CAPE), etc.]. Thus, determining the effects of aerosols based on observations is thought to be challenging because of the potential covariability of the relevant parameters and the small response suggested by many of the aforementioned modeling studies for identical environments.

In this work, we constrain the potential impacts of increased aerosol loading on deep convective clouds in the context of changes in the ambient environment and natural variability of convection. To do this over a large parameter space and to limit the number of degrees of freedom that complicate the predicted evolution of deep convective clouds, a more simplistic framework compared to that used in previous aerosol-cloud interaction studies on deep convection is employed. The framework discussed in the following section provides an approach that reduces complexity and provides an upper bound for the overall effect, assuming that the dynamical feedbacks are not substantial; Grabowski (2015) suggests that this is a plausible assumption.

The remainder of the paper is organized as follows: Section 2 describes the numerical method, cases, and analysis techniques. Section 3 presents the analysis of the simulations, while a discussion of the aggregated results is presented in section 4 . Last, section 5 includes detailed conclusions and a discussion of the implications of the main findings.

\section{Methodology}

\section{a. Numerical method}

We follow the numerical method employed by both Parker (2010) and Morrison (2016b). The method requires a solution for the perturbation pressure, which is of particular importance for deep convective clouds (e.g., Doswell and Markowski 2004; Markowski and Richardson 2010); its equation can be derived from the inviscid, anelastic momentum equation to obtain (e.g., Klemp 1987)

$$
\nabla^{2} p^{\prime}=\nabla^{2} p_{D}^{\prime}+\nabla^{2} p_{B}^{\prime}=-\nabla \cdot(\bar{\rho} \mathbf{v} \cdot \nabla \mathbf{v})+\frac{\partial \bar{\rho} B}{\partial z} .
$$

Here, $\mathbf{v}$ is the $3 \mathrm{D}$ wind vector; $p^{\prime}$ is the perturbation pressure, which is decomposed into dynamical and 
buoyancy components ( $p_{D}^{\prime}$ and $p_{B}^{\prime}$, respectively); $\bar{\rho}$ is the base-state air density; and $B$ is buoyancy, which is assumed to be a function of height $z$. The effects of hydrometeor loading on $B$ are neglected in this study; because hydrometeor loading provides a negative buoyancy contribution to a parcel, the $B$ profiles used herein represent the upper limits for each scenario.

The dynamical pressure perturbation has received considerable attention in the literature (e.g., Weisman 1993; Szeto and Cho 1994; Parker and Johnson 2004; Peters 2016); however, when including this term in an idealized framework, obtaining a solution is rather difficult, albeit possible with some simplifications as discussed in Peters (2016). However, for consistency with Parker (2010) and Morrison (2016b), we focus on the buoyancy contribution; by neglecting the contribution of the dynamic pressure perturbation, the results are more relevant for weakly sheared environments because strongly sheared environments (which result in squall lines and supercells) tend to have larger dynamic pressure perturbations (e.g., Parker and Johnson 2004). This assumption allows us to simplify Eq. (1) to

$$
\nabla^{2} p^{\prime} \approx \nabla^{2} p_{B}^{\prime}=\frac{\partial \bar{\rho} B}{\partial z} .
$$

The solution to Eq. (2) follows that of Morrison (2016b) for a given $B$ profile. The $B$ profile must be distributed horizontally to represent the width of a convective updraft. This is performed using a simple cosine function, such that $B(r)=B \cos [\pi r /(\Delta x)]$, where $r=\sqrt{\left(x-x_{0}\right)^{2}+\left(y-y_{0}\right)^{2}}$ is the distance from point $\left(x_{0}, y_{0}\right)$, which is the center of the domain for an upright profile, and $\Delta x$ is the prescribed width of the buoyancy profile (updraft width). Morrison (2016b) used additional distribution functions and found similar results for each function. For the upright updraft simulations, $x_{0}$ is constant with height; however, for the tilted updraft cases, we first locate the height of maximum $B$ and use that as the pivot point for shifting $x_{0}$, which represents the center of the $B$ profile, based on the prescribed slope $(S=\cos \alpha$, where $\alpha$ represents the angle of the tilt in the buoyancy profile relative to the vertical, i.e., $\alpha=0^{\circ}$ and $90^{\circ}$ for an upright and horizontal buoyancy profile, respectively).

Equation (2) is solved for $p_{B}^{\prime}$ on a $3 \mathrm{D}$ grid using a multigrid iterative solver (Adams 1999) with 129 points in each direction (the results presented below in terms of relative changes in the maximum updraft velocity are insensitive to the number of points in each direction). The physical distance between points is adjusted for the different buoyancy profile widths (discussed in the following paragraph) such that the total domain width is a factor of 10 larger than the width of the positively buoyant zone. Following Holton (1973) and Morrison (2016b), the horizontal boundaries are assumed to be periodic, while the upper and lower boundaries are prescribed to be $p_{B}^{\prime}=0$ and $\partial p_{B}^{\prime} / \partial z=0$, respectively. The selected boundary condition of $p_{B}^{\prime}=0$ is intended to represent the top of the atmosphere where the pressure tends to 0 ; although small accelerations can occur at the domain top because of the lack of double Neumann boundary conditions, these have a negligible effect on the derived vertical accelerations in the convective core (not shown).

Using the following simplified vertical momentum equation (inviscid, incompressible fluid with constant density),

$$
\frac{D w}{D t}=-\frac{1}{\rho} \frac{\partial p_{B}^{\prime}}{\partial z}+B
$$

we convert the derived $p_{B}^{\prime}$ field and $B$ profile into vertical accelerations. The accelerations are used to determine updraft velocities based on the analysis technique discussed in section $2 \mathrm{~d}$.

\section{b. The B calculations}

The $B$ profiles needed to solve for $p_{B}^{\prime}$ are derived using pseudoadiabatic parcel theory, in which an air parcel is lifted from the surface to the lifting condensation level (LCL) following the dry adiabatic lapse rate, and then lifted further following the moist adiabatic lapse rate, assuming steady-state conditions. The difference between the parcel's derived temperature and the environmental temperature, including the virtual effect of water vapor, is used to calculate $B$ at any given level. The assumption of steady-state conditions suggests that convection follows steady plumes; however, in radiative-convective equilibrium, convection occurs via local transient thermals (e.g., Sherwood et al. 2013; Romps and Charn 2015; Hernandez-Deckers and Sherwood 2016). Although the assumption of steadystate conditions is a simplification of the real state of convection, we select this option for consistency with prior similar works (e.g., Parker 2010; Morrison 2016b). Another aspect of this simplification that deserves attention is the scale height $H$, which is approximately $10 \mathrm{~km}$ based on the parcel theory calculations. This is important because the vertical acceleration of parcels in convective cores is expected to be related to the aspect ratio of the updraft $(H / \Delta x)$, as shown by Morrison (2016a) and Jeevanjee and Romps (2016). For smaller scale heights, parcel accelerations are limited, which ultimately limits the maximum updraft velocity. Moreover, reducing the scale height would limit the effects of aerosol-induced warming by decreasing the consumed CAPE, which in addition to the 
steady-state assumption described above, indicates that the approach applied herein constrains the potential response in updraft velocity to changes in aerosol loading by providing an upper limit.

Furthermore, the aforementioned approach assumes that a rising parcel of air remains adiabatic; that is, the effects of entrainment/detrainment are neglected. Thus, to mimic these effects, we utilize an additional scenario to represent subadiabatic parcel ascent. Here, a rising parcel is assumed to be adiabatic at the LCL; the adiabaticity decreases following an inverse-height relationship to mimic the effects of entraining environmental air on a rising parcel. The use of such a relationship is common for specifying entrainment/detrainment rates (e.g., Jakob and Siebesma 2003; Zhang 2009; Wu 2012). The formulation is straightforward, namely, that the fractional adiabaticity $f_{\text {ad }}$ is defined relative to the height above cloud base $z_{c}$ and a predefined constant $z_{0}$ :

$$
f_{\text {ad }}=\frac{z_{0}}{z_{0}+z_{c}}
$$

Based on this definition, $f_{\text {ad }}=1$ (adiabatic) at cloud base (i.e., $z_{c}=0 \mathrm{~m}$ ) and approaches 0 for an infinitely tall cloud; $f_{\text {ad }}$ is used to adjust the lapse rate using a linear combination of the dry and moist adiabatic lapse rates with contributions determined by $1-f_{\mathrm{ad}}$ and $f_{\mathrm{ad}}$, respectively. For the purpose of this study, $z_{0}$ was set to $30 \mathrm{~km}$, which resulted in subadiabatic profiles that were similar to those obtained by Morrison (2017) and integrated condensed water amounts that were approximately $50 \%-75 \%$ of the adiabatic values at the equilibrium level (e.g., Freud and Rosenfeld 2012). In reality, entrainment occurs as a series of quasi-stochastic mixing events as environmental air is mixed with the convective updraft (e.g., Romps 2016). However, the idealized inverse-height relation results in a profile that allows for numerical solutions to Eq. (2) and an investigation of the potential impacts of subadiabaticity on updraft velocities due to changes in both the environment and increased aerosol loading (or increased warming due to phase changes).

\section{c. Sensitivity to warming and updraft width and slope}

The updraft width is varied by adjusting $\Delta x$, which is the width of the $B$ profile. We employ a wide range of $\Delta x$, namely, $2-16 \mathrm{~km}$ at $2-\mathrm{km}$ intervals, which is on the lower end of $\Delta x$ explored by Morrison (2016b) but focuses on the range over which the largest changes occur. This range also encompasses the simulated updraft widths in Lebo and Morrison (2015) and the range of widths identified by Ziegler et al. (2010). Furthermore, $S$ is varied by adjusting the "center" of the buoyancy profile at each level. To define the range of $S$, we use 6 values of $\alpha$ (see section 2a) ranging from $0^{\circ}$ to $68^{\circ}$, corresponding to $S$ between 1 and 0.37 , which encompasses the range simulated for realistic wind shear profiles in a squall line by Lebo and Morrison (2014) and used in Parker (2010); the corresponding shear used in Lebo and Morrison (2014) to obtain these slopes coincide with the range of shear values observed in nature (e.g., Rasmussen and Blanchard 1998).

To simulate the effects of aerosol-induced warming via phase changes, which is expected to occur under the conventional mixed-phase (e.g., Rosenfeld et al. 2008) and warm (e.g., Sheffield et al. 2015; Lebo 2014) invigoration hypotheses, we simulate instantaneous warming $(\Delta T)$ for a rising parcel of air at 5 levels: the height at which the temperature reaches $10^{\circ} \mathrm{C}$ (which is near cloud base), $4^{\circ} \mathrm{C}$ (which is above cloud base but below the freezing level, intended to represent the time-dependent nature of microphysical processes in updrafts), $-4^{\circ} \mathrm{C}$ (which is the assumption applied in Rosenfeld et al. 2008), $-15^{\circ} \mathrm{C}$ (which is based on a more realistic level at which liquid is expected to begin freezing in clouds via heterogeneous freezing; e.g., Boudala et al. 2004; Kanitz et al. 2011; Murray et al. 2012), and $-35^{\circ} \mathrm{C}$ (representing the extreme scenario in which liquid remains supercooled until nearly reaching the homogeneous freezing level). To determine the range of $\Delta T$ to be used for the suite of simulations, a (representative albeit not complete) survey of the recent literature was conducted. Herbener et al. (2014) found a slight increase near cloud base $\left(<0.5^{\circ} \mathrm{C}\right)$ and a cooling aloft due to enhanced aerosol loadings in convection associated with a tropical cyclone. Moreover, Lebo (2014) showed increases in the latent heating by no more than $1^{\circ} \mathrm{Ch}^{-1}$, all of which was confined below the freezing level, based on simulations of a continental squall line. Khain and Lynn (2009) showed an increase in the ice water content due to increased aerosols in a numerically simulated supercell of at most $0.5 \mathrm{~g} \mathrm{~m}^{-3}$, the freezing of which would have resulted in less than $0.5^{\circ} \mathrm{C}$ of warming. Lee (2012) showed an even smaller warming due to increased aerosol loading of only $0.1^{\circ} \mathrm{Cday}^{-1}$ based on simulations of a mesoscale convective system (MCS) observed during the Tropical Warm Pool International Cloud Experiment (TWP-ICE). The outlier is Sheffield et al. (2015), who found a nearly $0.1^{\circ} \mathrm{Cmin}^{-1}$ increase in the latent heating rate due to increased aerosol loading; however, this work focused more on cumulus congestus than mature deep convection. Note the difference in units between the two prior references (i.e., per day vs per minute). Relating changes in warming related to phase changes to overall temperature changes is challenging because these convective systems are typically 
transient. If the warming were to be applied for $1 \mathrm{~h}$, the range of warming rates extracted from the literature would result in net warmings of $0.004^{\circ}-6^{\circ} \mathrm{C}$. Again, it is important to note that the upper limit is based on cumulus congestus and not mature deep convection that is the focus of many aerosol-cloud-precipitation interaction studies; thus, we limit the upper bound slightly. Based on these works, we simulate a wide range of $\Delta T: 0^{\circ}-5^{\circ} \mathrm{C}$ at $1^{\circ} \mathrm{C}$ intervals (corresponding to the freezing of $0-15.06 \mathrm{~g} \mathrm{~kg}^{-1}$ of liquid, the condensation of $0-2.01 \mathrm{~g} \mathrm{~kg}^{-1}$ of vapor, or the deposition of $0-1.77 \mathrm{~g} \mathrm{~kg}^{-1}$ of vapor). However, the focus of the analysis will be on the lower end of the $\Delta T$ range based on the majority of the research in the literature.

In reality, $\Delta T$ is likely to be distributed over the vertical because of the time-dependent nature of freezing (e.g., Pruppacher and Klett 1997; Kumjian et al. 2012; Phillips et al. 2014, 2015) and both condensation and deposition; thus, at each level, the results presented in sections 3 and 4 are indicative of maximum responses for microphysical changes initiated at that level. Alternatively, one can view this approach as taking the summative change in warming ${ }^{1}$ over the vertical extent of a parcel's ascent above the selected warming level (which has been shown to be important in prior studies; e.g., Lebo et al. 2012) and applying it at a single level, which again represents a maximum possible response.

Three soundings are employed, resulting in 4320 simulations covering the parameter space for each adiabaticity scenario. The soundings include a well-observed squall line over Oklahoma (OK; e.g., Lebo and Morrison 2014), the commonly used Weisman-Klemp supercell sounding (WK; Weisman and Klemp 1982), and a tropical sounding (TC; Jordan 1958).

\section{d. Analysis of changes in updraft velocity compared with theoretical expectations}

The aforementioned numerical methodology provides a useful tool to determine the vertical acceleration following a parcel, namely, Dw/Dt. Following Parker (2010), a simple forward integration approach is used to derive the maximum updraft velocity $w_{\max }$ (where changes in $w_{\max }$ due to changes in the various parameters are the focus of this work) by initializing a parcel at the lowest level in which $D w / D t>0$ and integrating until $D w / D t<0$ following the center of the $B$ profile (i.e., the location in which $B$ is a maximum in the horizontal).

\footnotetext{
${ }^{1}$ Here, summative warming is the increase in temperature due to all microphysical processes involving a change of phase, including condensation, ice nucleation, riming, and deposition, although the latter is smaller than it first appears because one must subtract the warming from condensation that would have occurred otherwise, leaving a much smaller contribution.
}

Based on the derived $w_{\max }$ values for all solutions, we can determine the change in $w_{\max }\left(\Delta w_{\max }\right)$ for a given $\Delta T$ by taking the difference between $w_{\max }$ for that $\Delta T$ and $w_{\max }$ in the absence of warming (holding all other parameters constant). This difference is useful for comparison with the expected theoretical change in $w_{\max }$ due to added warming $\left(\Delta w_{\text {max,th }}\right)$. To derive $\Delta w_{\text {max,th }}$ from the $B$ profiles, we note that the theoretical $w_{\max }\left(w_{\max , \text { th }}\right)$ is equivalent to $\sqrt{2 \mathrm{CAPE}}$. Differentiating and rearranging results in the following expression:

$$
\Delta w_{\text {max }, \text { th }}=\frac{1}{2} \frac{\Delta \mathrm{CAPE}}{\mathrm{CAPE}} w_{\max } .
$$

Here, we use $w_{\max }$ so that $\Delta w_{\text {max,th }}$ and $\Delta w_{\max }$ represent changes from the same baseline vertical velocity. Because of the inclusion of the effects of $p_{B}^{\prime}$ on $w_{\max }$, it is expected that $\Delta w_{\max }$ will be less than $\Delta w_{\text {max th }}$.

\section{Results}

Illustrative examples of the buoyancy field, derived $p_{B}^{\prime}$ field, and resulting acceleration vectors are shown in Fig. 1 for a small portion of the derived solutions. Relevant parameters for the individual simulations are shown above each panel. Comparing Figs. 1a and $1 \mathrm{~b}$ reveals that an increase in $\Delta x$ results in a decrease in $w_{\max }$, which agrees with Markowski and Richardson (2010) and Morrison (2016b); this decrease can be attributed to an increase in the $p_{B}^{\prime}$ gradient aloft. The effects of $S$ are indicated by comparing Figs. 1a and 1c, where increasing $S$ decreases $w_{\max }$ because of the increased $p_{B}^{\prime}$ gradient in the vertical, which agrees with the findings of Parker (2010). Next, comparing Fig. 1a with Figs. $1 \mathrm{~d}-\mathrm{f}$ provides evidence of increased $w_{\max }$ for $\Delta T=2^{\circ} \mathrm{C}$ located at $10^{\circ},-4^{\circ}$, and $-15^{\circ} \mathrm{C}$, respectively (the changes in $B$ are subtle but do have an effect on the resulting $\left.w_{\max }\right)$. For the examples shown here, the increase in $w_{\max }$ is approximately $8.3 \mathrm{~m} \mathrm{~s}^{-1}(11.2 \%)$ for $2^{\circ} \mathrm{C}$ warming at $10^{\circ} \mathrm{C}, 4.2 \mathrm{~m} \mathrm{~s}^{-1}(5.7 \%)$ at $-4^{\circ} \mathrm{C}$, and $2.2 \mathrm{~m} \mathrm{~s}^{-1}(2.9 \%)$ at $-15^{\circ} \mathrm{C}$. Note that the values of $w_{\max }$ are high largely because of the assumption of adiabatic parcel ascent; the effects on subadiabatic parcel ascent are discussed later in this section.

A useful comparison is between $\Delta w_{\max }$ shown in Figs. 1d-f (as well as those for all other parameter combinations) and $\Delta w_{\text {max,th }}$ because of warming, which is shown in Fig. 2 for both the adiabatic and subadiabatic profiles and all three soundings. As noted in section $2 \mathrm{~d}$, $\Delta w_{\max }$ is dependent on all parameters (sounding, adiabaticity, warming, and both updraft width and slope); thus, for warming at a given level, there is some variability in the results even for a given sounding and adiabaticity assumption, which is reflected by the scatter 

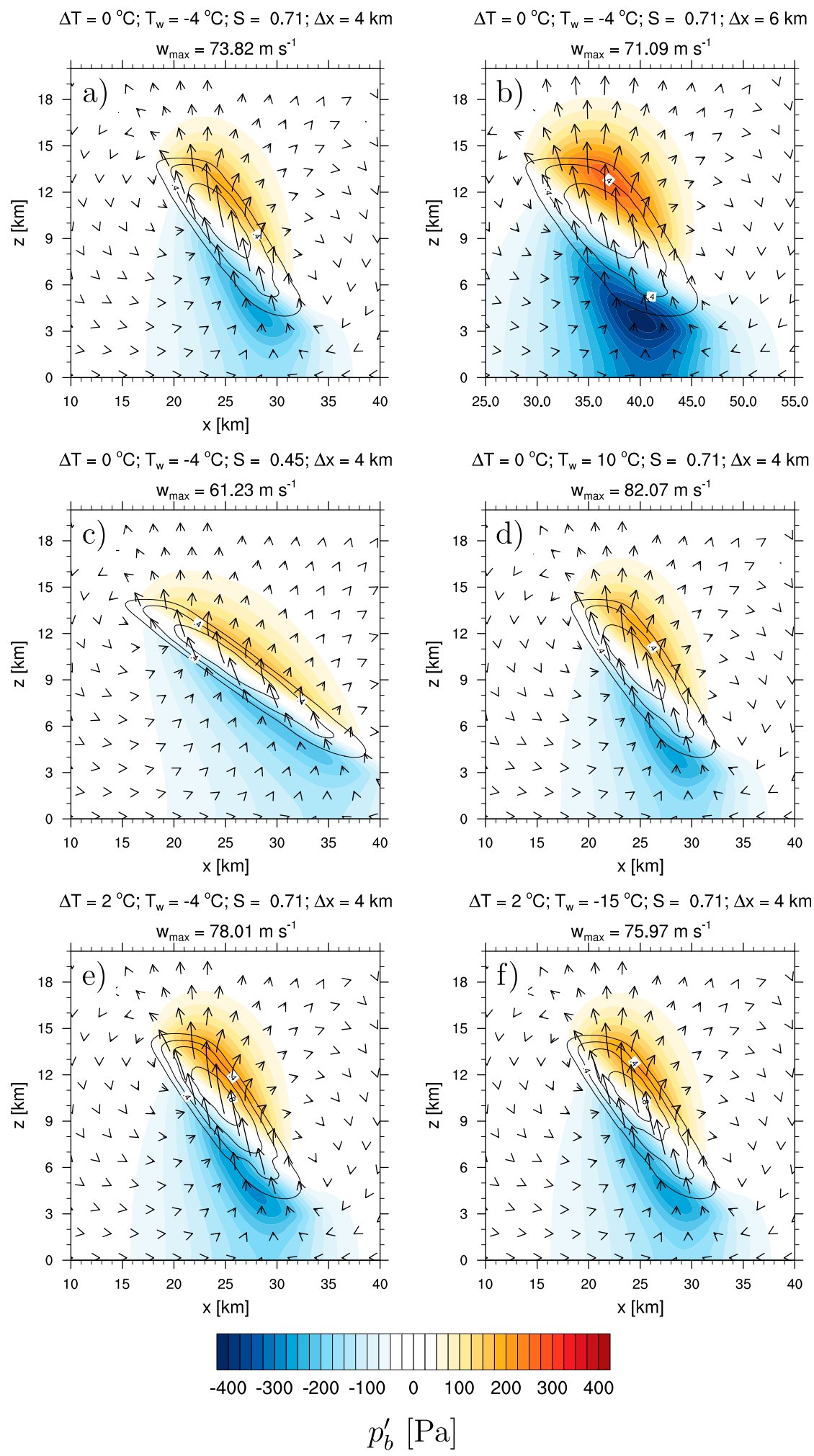

FIG. 1. (a)-(f) Example solutions for the OK sounding. The effect of changes in $\Delta x$ [cf. (a) and (b)], $S$ [cf. (a) and (c)], warming at $10^{\circ} \mathrm{C}$ [cf. (a) and (d)], warming at $-4^{\circ} \mathrm{C}$ [cf. (a) and (e)], and $\Delta T$ at $-15^{\circ} \mathrm{C}$ [cf. (a) and (f)]. Colors show $p_{B}^{\prime}$ (cool: negative; warm: positive). Contoured is the buoyancy field (intervals of $0.2 \mathrm{~m} \mathrm{~s}^{-2}$ ). Vectors show acceleration. 
OK Squall Line
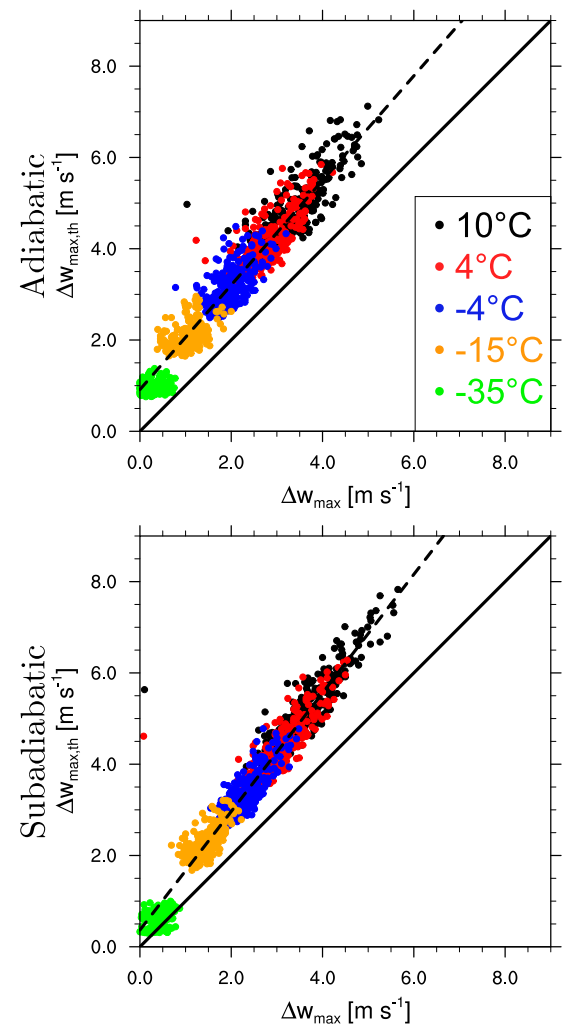

Tropical Cyclone
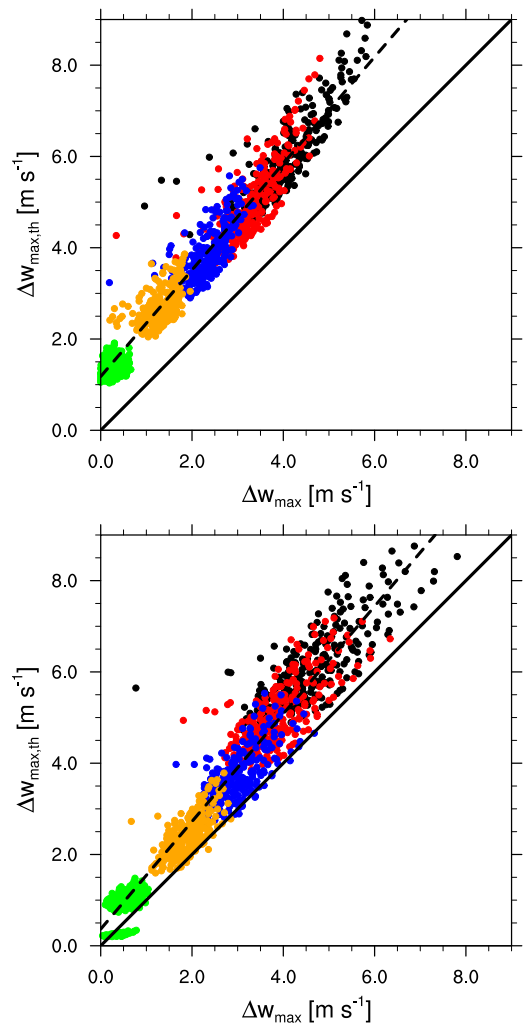

Weisman and Klemp (1982)
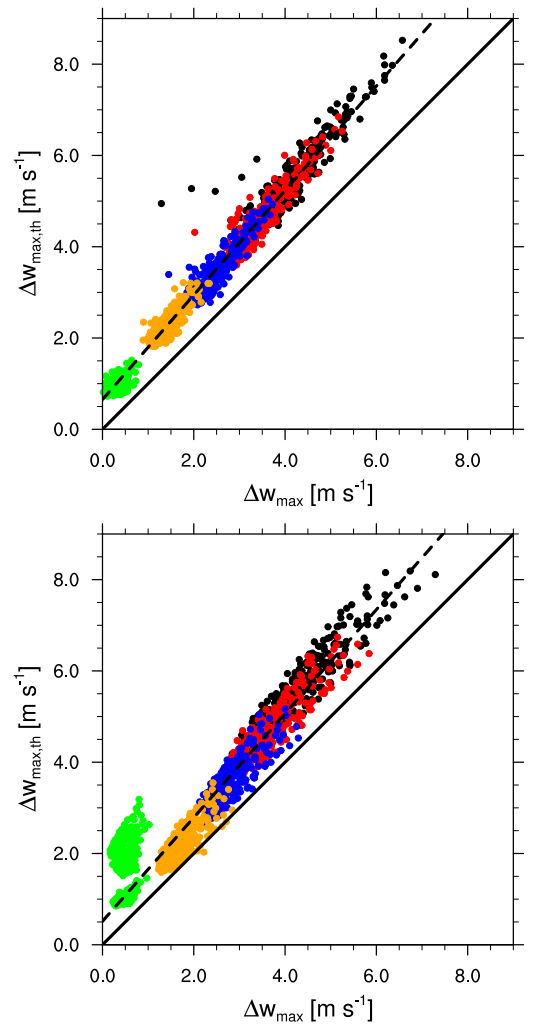

FIG. 2. Comparison of theoretical changes in $w_{\max }\left(\Delta w_{\max , \text { th }}\right)$ based on changes in $\sqrt{2 \mathrm{CAPE}}$ and $\Delta w_{\max }$ from the numerical solutions, as outlined in section $2 \mathrm{~b}$. The colors correspond to warming at $10^{\circ}$ (black), $4^{\circ}$ (red), $-4^{\circ}$ (blue), $-10^{\circ}$ (orange), and $-35^{\circ} \mathrm{C}$ (green). The solid line corresponds to the 1:1 line, and the dashed line is the best-fit line through the points. For each color, the variability is related to different combinations of $S$ and $\Delta x$ (because $\Delta w_{\max }$ is not a constant for each pair of $S$ and $\Delta x$ values) and to different $\Delta T$.

in the points of a particular color in Fig. 2. Overall, the points depicted in Fig. 2 generally lie above the 1:1 line, indicating that $\Delta w_{\max , \text { th }}>\Delta w_{\max }$ - the change in vertical velocity due to added warming (assumed to be from the enhanced release of latent energy due to phase changes) is less than that expected from theoretical arguments alone by as much as a factor of 2 under some circumstances. This suppression in $\Delta w_{\max }$ is caused by the inclusion of the buoyancy perturbation pressure gradient in the derived $w_{\max }$ values. Figure 2 also highlights the importance of the level at which the warming occurs, with a clear decrease in the effect on $w_{\max }$ as the warming occurs at higher levels; the largest impact is found for warming near cloud base (i.e., at $10^{\circ} \mathrm{C}$ ), highlighting the potential importance of warm invigoration, especially compared to mixed-phase invigoration.

Furthermore, the aforementioned changes in $w_{\max }$ are smaller than those suggested in Rosenfeld et al. (2008) in the context of conventional mixed-phase invigoration (i.e., because of warming above the freezing level). For comparison, Rosenfeld et al. (2008) showed an increase in consumed CAPE of approximately $1000 \mathrm{~J} \mathrm{~kg}^{-1}$ because of mixed-phase invigoration; here, the range in $\Delta T$ results in increases in consumed CAPE of 2476, 3465, and $3580 \mathrm{~J} \mathrm{~kg}^{-1}$ for the WK, OK, and TC soundings, respectively, with an increase of $1000 \mathrm{~J} \mathrm{~kg}^{-1}$ occurring for warmings of approximately $1.5^{\circ}, 1.5^{\circ}$, and $2.0^{\circ} \mathrm{C}$, respectively. The reasons for the reduction in $w_{\max }$ compared with Rosenfeld et al. (2008) are threefold: 1) buoyancy perturbation pressures are considered, which were neglected in Rosenfeld et al. (2008); 2) differences in soundings [i.e., low-CAPE tropical sounding in Rosenfeld et al. (2008) vs more energetic soundings herein]; and 3) more realistic freezing temperatures are examined compared with Rosenfeld et al. (2008), who used $-4^{\circ} \mathrm{C}$ as the only freezing level in their numerical simulations. The buoyancy perturbation pressure accounts for up to a factor of 2 of the decrease in $w_{\max }$ compared to that obtained from simply examining the difference in CAPE for soundings with and without warming induced by the lofting of additional condensate above the freezing level and subsequent differences in latent energy released to the environment, which 
OK Squall Line
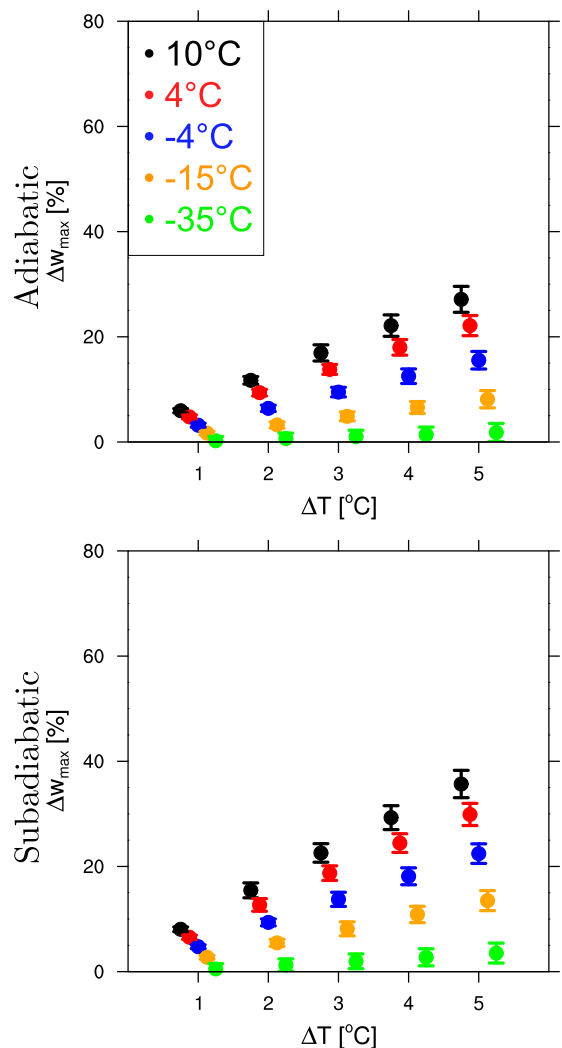

Tropical Cyclone
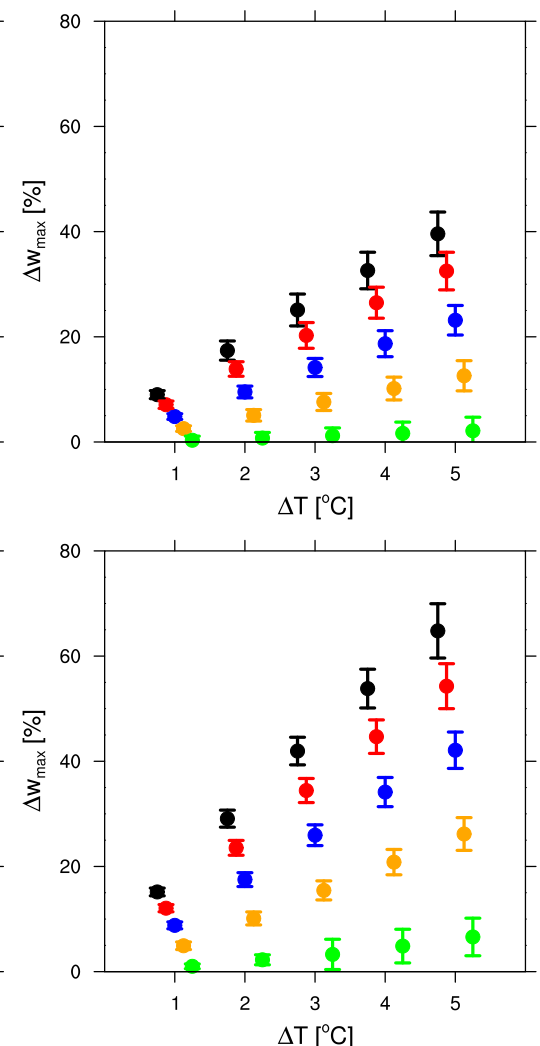

Weisman and Klemp (1982)
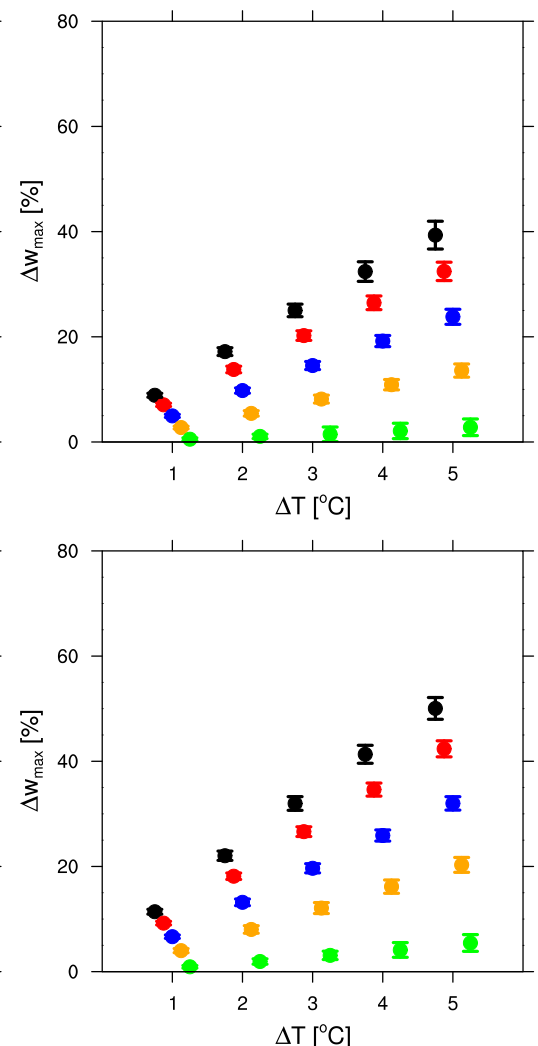

FIG. 3. Absolute change in $w_{\max }$. (top) Adiabatic and (bottom) subadiabatic are shown for the (left) OK, (center) TC, and (right) WK cases. The filled circles denote the mean change; the bars denote \pm 1 standard deviation. The colors correspond to warming at $10^{\circ}$ (black), $4^{\circ}$ (red), $-4^{\circ}$ (blue), $-15^{\circ}$ (orange), and $-35^{\circ} \mathrm{C}$ (green). For each $\Delta T$, the points are shifted left and right for clarity.

formed the basis of the results in Rosenfeld et al. (2008; Fig. 2). The difference in soundings accounts for a large portion of the differences between the current study and Rosenfeld et al. (2008). For example, assuming a lowCAPE sounding with approximately $1500 \mathrm{~J} \mathrm{~kg}^{-1}$, an increase in the consumed potential energy by $1000 \mathrm{~J} \mathrm{~kg}^{-1}$ due to warming aloft would result in a $29.1 \%$ increase in $w_{\text {max }}$; the same increase in the consumed potential energy for a sounding with $4000 \mathrm{~J} \mathrm{~kg}^{-1}$ results in only an $11.8 \%$ increase in $w_{\max }$. Last, the effect of freezing at more realistic temperatures also substantially reduces $\Delta w_{\max }$ due to added warming aloft because it limits the increase in $B$, which has a direct effect on limiting the effect of warming on $w_{\max }$.

A more complete portrayal of $\Delta w_{\max }$ for the various $\Delta T$ and locations of the applied warmings is shown in Fig. 3, which depicts the mean $\Delta w_{\max }$ (denoted by dots) and the variability induced by changes in $S$ and $\Delta x$ (bars are \pm 1 standard deviation) for a given $\Delta T$ ( $x$ axis) applied at a specific temperature (colors). For all soundings and both the adiabatic and subadiabatic profiles, $\Delta T$ of $1^{\circ} \mathrm{C}$ results in approximately a $10 \%$ increase in $w_{\max }$ at most for warm invigoration at $10^{\circ} \mathrm{C}$ (except for the $\mathrm{TC}$ sounding under subadiabatic conditions, where the effect increases to approximately $17 \%)$. As $\Delta T$ increases, so does $\Delta w_{\max }$, as discussed in the sample of the results presented in Fig. 1. This is because the effects of $\Delta T$ on $B$ are nonlinearly related to $p_{B}^{\prime}$ [Eq. (2)] and the resulting gradient in $p_{B}^{\prime}$, which affects the vertical acceleration and resulting $w_{\max }$. For mixed-phase invigoration at $-4^{\circ} \mathrm{C}, \Delta w_{\max }$ is very small on average for $\Delta T$ of $1^{\circ} \mathrm{C}$, reaching a maximum of $5 \%$ for the TC sounding under subadiabatic conditions. For comparison, a similar $\Delta w_{\max }$ would be expected for a $10 \%$ increase in CAPE based on simple thermodynamic arguments (i.e., $w_{\text {max,th }}$ goes as $\sqrt{2 \mathrm{CAPE}})$. Thus, if the spatial variability of CAPE exceeds $10 \%$ of the mean, the resulting differences in $w_{\max }$ are likely to exceed the effects of a $\Delta T$ of $1^{\circ} \mathrm{C}$ at $-15^{\circ} \mathrm{C}$, making observations of the mixed-phase invigoration effect very difficult in nature. However, if $\Delta T$ were higher (e.g., $5^{\circ} \mathrm{C}$ for the $\mathrm{TC}$ sounding under subadiabatic conditions, which results in the large $\Delta w_{\max }$ of $65 \%$, albeit such a warming seems unlikely given the literature review discussed in section $2 \mathrm{c}$ ) or located at 

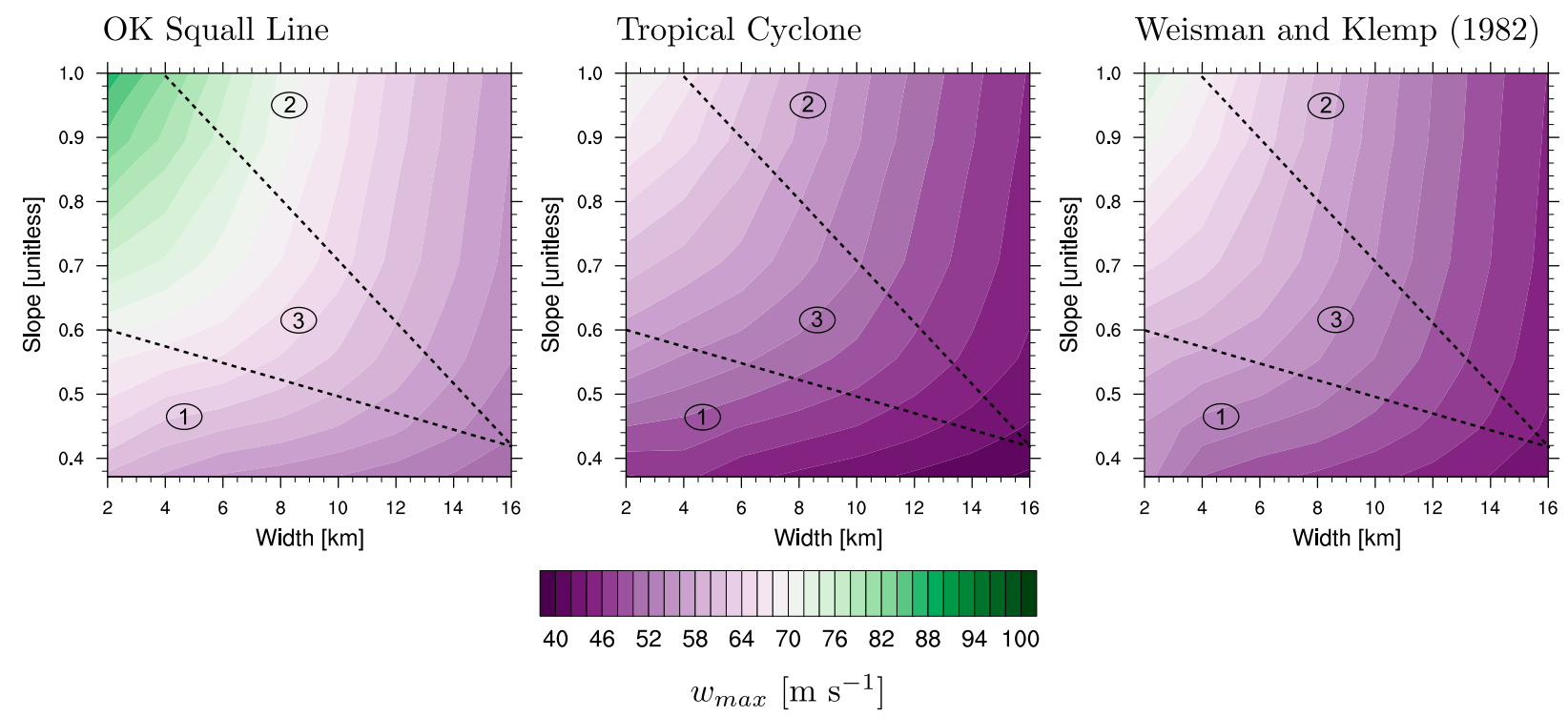

FIG. 4. Slope vs width parameter space contours of $w_{\max }$ (colored) for the (left) OK, (center) TC, and (right) WK soundings; the results are depicted assuming no added warming aloft. The same color bar applies to all panels to aid in the comparison; each color represents a range of $2 \mathrm{~m} \mathrm{~s}^{-1}$. The dashed lines demarcate approximate boundaries between different regions of the parameter space; the numbers correspond to the parameter space characteristics defined in section $3 \mathrm{a}$.

higher temperatures (i.e., warm invigoration), the effects of warming due to the effects of aerosol are expected to be larger.

\section{a. Individual parameter spaces}

The above analysis focused on a selected set of solutions for a given sounding as well as the difference between $\Delta w_{\max }$ and $\Delta w_{\max }$ th for warming imposed at different levels and for different $\Delta T$. In the following, we take a closer look at the effects of $S, \Delta x$, and $\Delta T$ by exploring the individual parameter spaces.

\section{1) $S-\Delta x$}

Morrison (2016b) examined the $\Delta x$ portion of the parameter space, whereas Parker (2010) focused on $S$; a combined exploration of the two parameters has not yet been conducted. These results are presented in Fig. 4; because of the definition of $S$, recall that 1 corresponds to upright updrafts, whereas smaller values indicate sloped updrafts. Regardless of the chosen sounding, the resulting $w_{\max }$ distribution within the $S-\Delta x$ parameter space is qualitatively the same, with the highest values occurring for the most upright and narrowest updrafts (in the absence of entrainment, which should increase with decreasing $\Delta x$ and increasing $S$ ), whereas the widest and most sloped updrafts have the smallest $w_{\max }$. This transition agrees with the combined results of Morrison (2016b) and Parker (2010). However, by combining changes in both $S$ and $\Delta x$, we can explore the entire parameter space in more detail than a simple combination of prior works that focused on the individual factors. Based on Fig. 4, the $S-\Delta x$ parameter space is more complex than suggested by the effects of the individual factors themselves. There are three main regions of the parameter space: 1 ) regions where $w_{\max }$ is insensitive to changes in $\Delta x, 2$ ) regions where $w_{\max }$ is insensitive to changes in $S$, and 3) regions where $w_{\max }$ is sensitive to both $S$ and $\Delta x$.

First, for $S$ less than approximately $0.6, w_{\max }$ is largely insensitive to changes in $\Delta x$ except for the widest of updrafts, meaning that small changes in $S$ have a larger effect on $w_{\max }$ than even large changes in $\Delta x$ in this region. Because the vertical acceleration is proportional to the vertical gradient in $p_{B}^{\prime}$ (in addition to the contribution from buoyancy), this result suggests that the vertical gradient in $p_{B}^{\prime}$ changes most rapidly because of changes in $S$ around $0.6-0.7$ (i.e., $43^{\circ}-56^{\circ}$ ). Second, $w_{\max }$ is rather insensitive to changes in $S$ for upright updrafts. For example, a change in $S$ from 1 to 0.8 (upright to $37^{\circ}$ ) in the case of the WK squall line sounding has nearly no effect on $w_{\max }$, whereas a change in $\Delta x$ by $\sim 1 \mathrm{~km}$ results in a decrease in $w_{\max }$ of approximately $2 \mathrm{~m} \mathrm{~s}^{-1}$. This result is qualitatively true for all three soundings, especially for wider updrafts. Third, regions where $w_{\max }$ is sensitive to both changes in $S$ and $\Delta x$ are largely confined to moderately sloped and upright updrafts with narrow to moderate updraft widths and highly sloped but very wide updrafts. These results indicate that the 

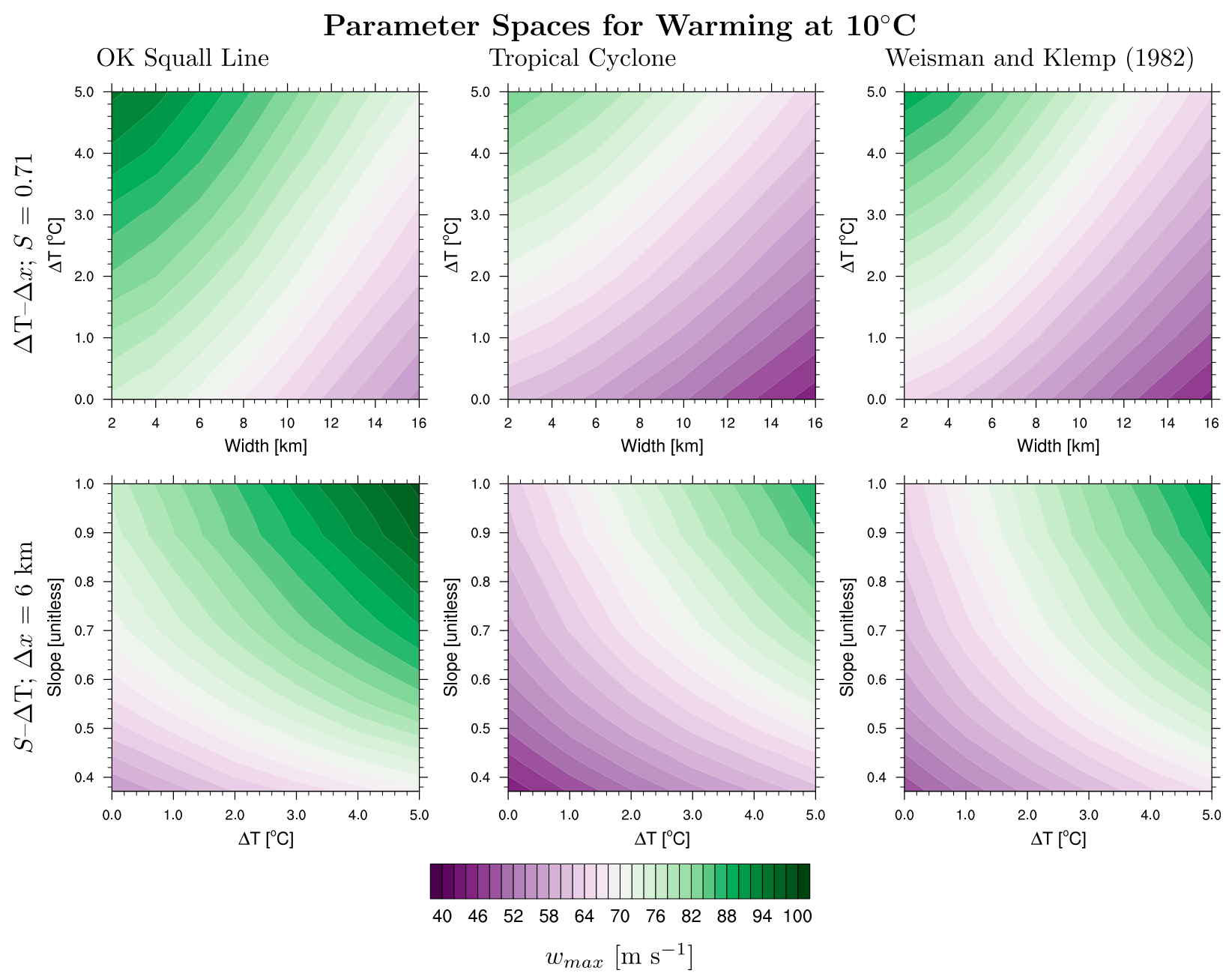

FIG. 5. Parameter space contours of $w_{\max }$ (colored) for the (left) OK, (center) TC, and (right) WK soundings assuming an instantaneous warming at a temperature of $10^{\circ} \mathrm{C}$ and adiabatic parcel accent. The same color bar applies to all panels to aid in the comparison; each color represents a range of $2 \mathrm{~m} \mathrm{~s}^{-1}$. For each row, the parameter space and the value of the third variable is shown to the left.

sensitivity of $w_{\max }$ to $\Delta x$ and $S$ is highly dependent on the values of $\Delta x$ and $S$.

\section{2) $\Delta x-\Delta T$}

The $\Delta x-\Delta T$ parameter space is shown in the top rows of Figs. $5-8$ for $\Delta T$ at $10^{\circ}, 4^{\circ},-4^{\circ}$, and $-15^{\circ} \mathrm{C}$, respectively (the parameter spaces are not shown for $-35^{\circ} \mathrm{C}$ based on the extremely low $\Delta w_{\max }$ values shown in Figs. 2 and 3; the same applies to the $S-\Delta T$ parameter space discussed in the following subsection). Across the parameter space, $w_{\max }$ changes by $18-20 \mathrm{~m} \mathrm{~s}^{-1}$, independent of the chosen sounding, although this range decreases as the warming is applied at lower temperatures, indicating the decreasing effect of aerosol-induced warming higher in the atmosphere (as denoted by the increasing slope of the contour lines from Fig. 5 to Fig. 8). Moreover, $w_{\max }$ is sensitive to both $\Delta T$ and changes in $\Delta x$ across the entire parameter space, with fairly similar sensitivity regardless of $\Delta x$ or $\Delta T$ except for the narrowest updrafts, where the effect of $\Delta T$ increases slightly (denoted by the flattening out of the contours). To provide a more quantitative description of the effects of $\Delta T$ in the context of $\Delta x$ based on the parameter spaces at each temperature level, we use the high-resolution modeling results of Lebo and Morrison (2015), who found an average $\Delta x$ of approximately $6 \mathrm{~km}$ with a standard deviation of $1.25 \mathrm{~km}$. Based on this average \pm 2 standard deviations (encompassing $95 \%$ of all cases assuming that $\Delta x$ is normally distributed), $\Delta T$ would have to exceed approximately $1^{\circ} \mathrm{C}$ to have a larger effect on $w_{\max }$ than the natural variability in $\Delta x$ for warming at $10^{\circ} \mathrm{C}$ (at least that based on the aforementioned high-resolution model simulations). At $-15^{\circ} \mathrm{C}$, the required warming increases to more than $2^{\circ} \mathrm{C}$. Given the relatively small changes in latent heating rates suggested in the 


\section{Parameter Spaces for Warming at $4^{\circ} \mathrm{C}$}

OK Squall Line
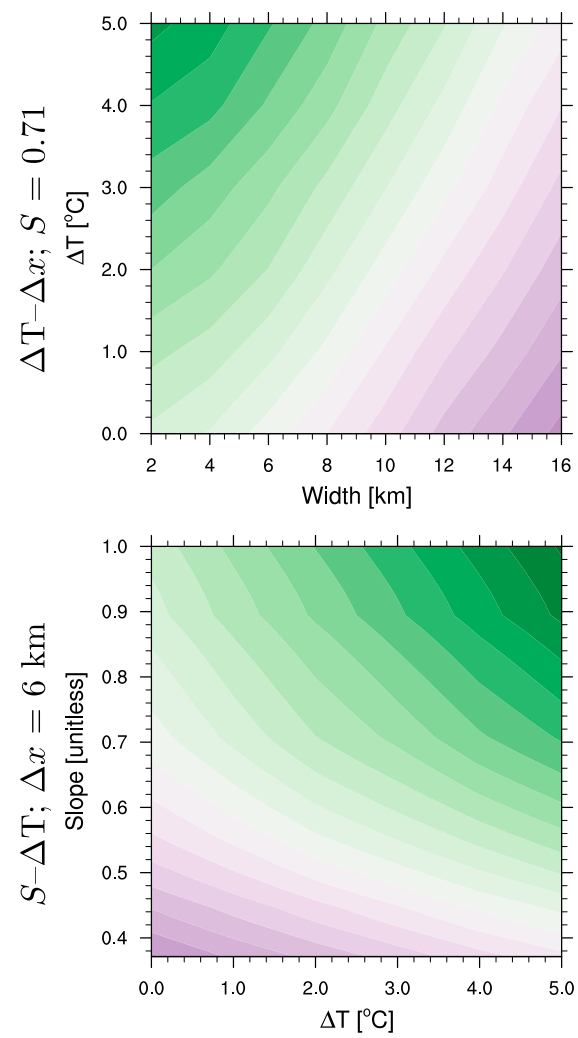

Tropical Cyclone
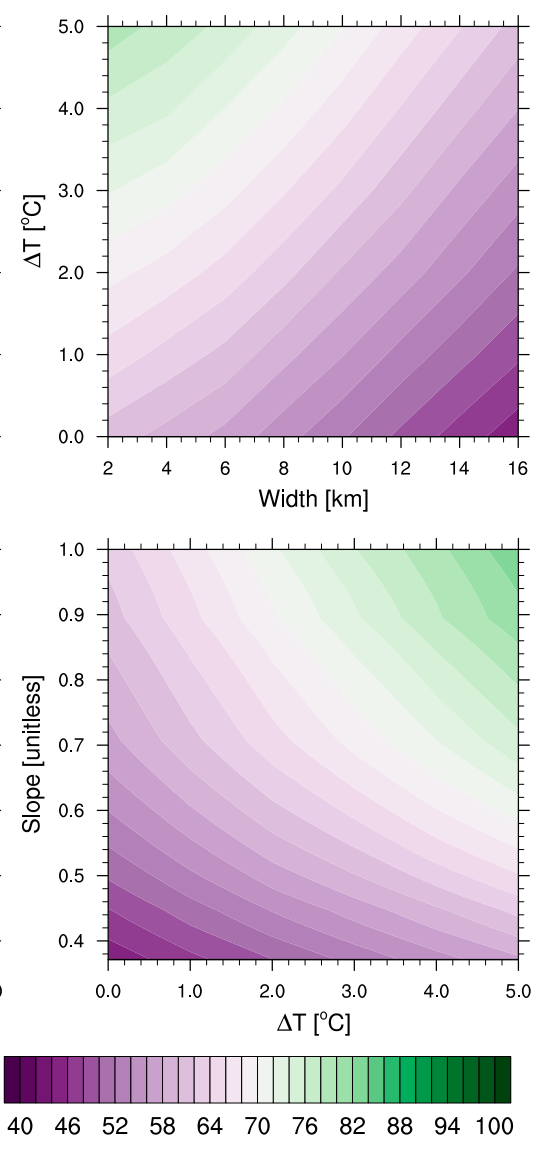

Weisman and Klemp (1982)
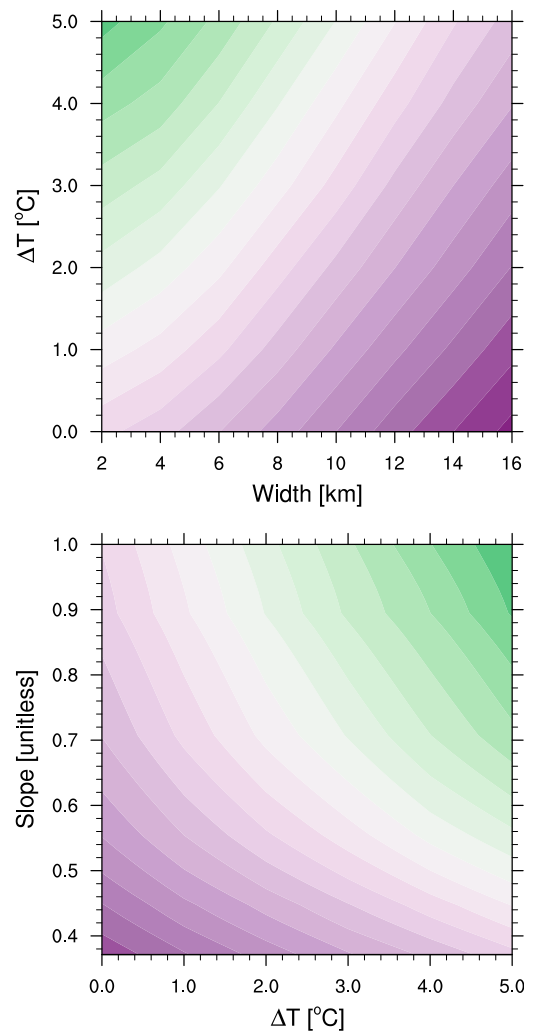

$w_{\max }\left[\mathrm{m} \mathrm{s}^{-1}\right]$

FIG. 6. As in Fig. 5, but assuming an instantaneous warming at a temperature of $4^{\circ} \mathrm{C}$.

literature and discussed in section 1 (e.g., Khain and Lynn 2009; Lee 2012; Herbener et al. 2014; Lebo 2014), these results indicate that the natural variability in $\Delta x$ will overwhelm any aerosol-induced changes in the thermal structure of a convective system, even in the case of warm invigoration (see section 4 for a more quantitative analysis). In nature, one important factor that strongly influences $\Delta x$ is low-level wind shear (e.g., Dennis and Kumjian 2017); a characterization of the natural spatial variability of low-level wind shear and its relation to convective updraft velocity variability is needed.

\section{3) $S-\Delta T$}

The $S-\Delta T$ parameter space is shown in the bottom rows of Figs. $5-8$ for $\Delta T$ at $10^{\circ}, 4^{\circ},-4^{\circ}$, and $-15^{\circ} \mathrm{C}$, respectively; $\Delta T$ has a larger impact on $w_{\max }$ for upright updrafts compared with sloped updrafts, especially in the case of mixed-phase invigoration at $-15^{\circ} \mathrm{C}$, where even $\Delta T$ of $5^{\circ} \mathrm{C}$ (corresponding to $15.06 \mathrm{~g} \mathrm{~kg}^{-1}$ of additional liquid that would have to freeze) results in a change in $w_{\max }$ of $4-6 \mathrm{~m} \mathrm{~s}^{-1}$ (or less than 10\%). This effect decreases as $S$ increases and the warming is applied at lower temperatures, again highlighting the potential importance of warm invigoration in comparison with the more widely cited mixed-phase invigoration.

Furthermore, for warm invigoration at $10^{\circ} \mathrm{C}$, a $1{ }^{\circ} \mathrm{C}$ warming at $S=0.71\left(\right.$ tilted $\left.45^{\circ}\right)$ has the same effect as a change in $S$ of approximately 0.15 for all soundings (the effect of $\Delta T$ increases for more upright updrafts and obviously larger $\Delta T$ ). Such a change in $S$ is extremely small (approximately $11.1^{\circ}$ ). For mixedphase invigoration at a freezing level of $-4^{\circ} \mathrm{C}$, the same warming for a similarly sloped updraft has the same effect as a change in $S$ by approximately 0.1 for all soundings. This change in $S$ is even smaller for warm invigoration (approximately $7.6^{\circ}$ ), especially when considering the change in shear needed to provide such a change in $S$ (i.e., approximately $1.2 \mathrm{~m} \mathrm{~s}^{-1}$ 


\section{Parameter Spaces for Warming at $-4^{\circ} \mathrm{C}$}

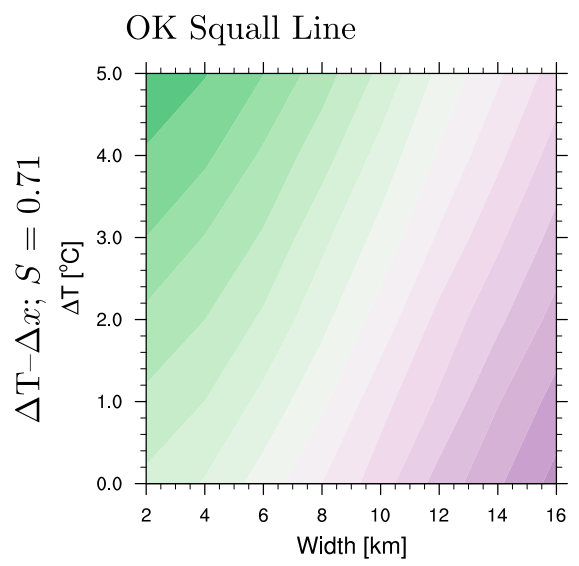

\section{Tropical Cyclone}
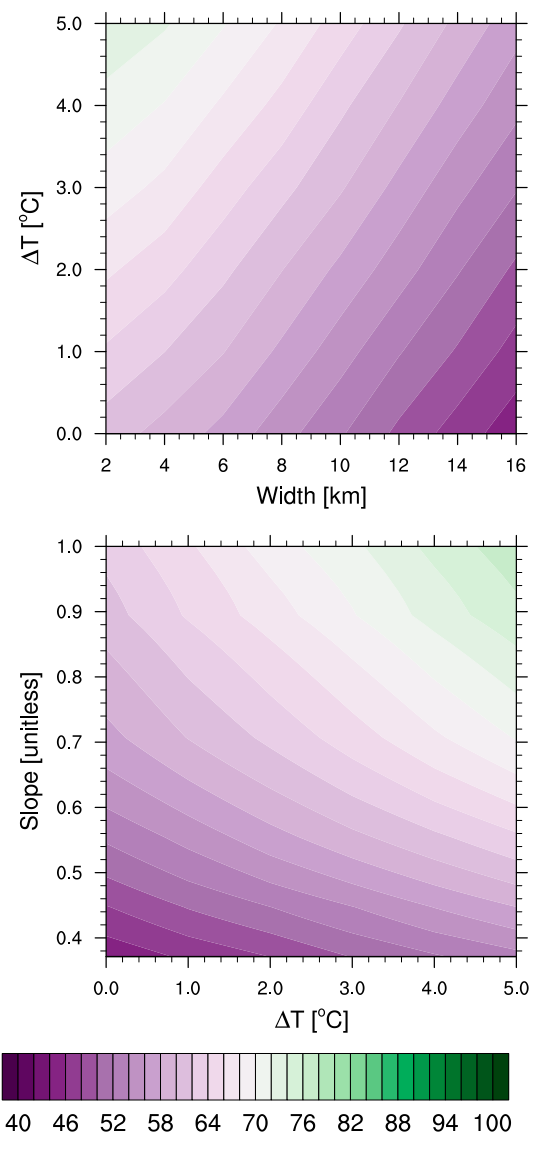

Weisman and Klemp (1982)
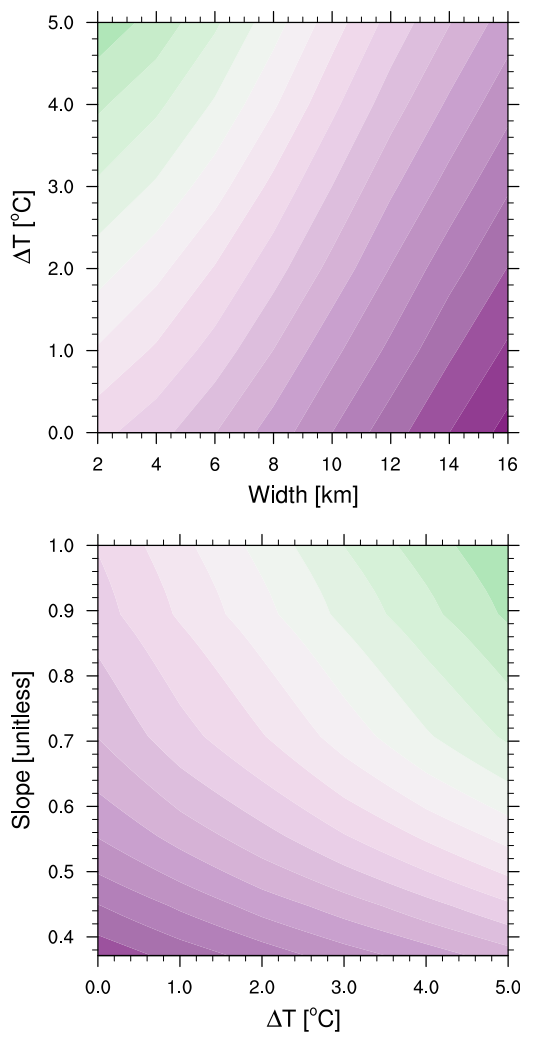

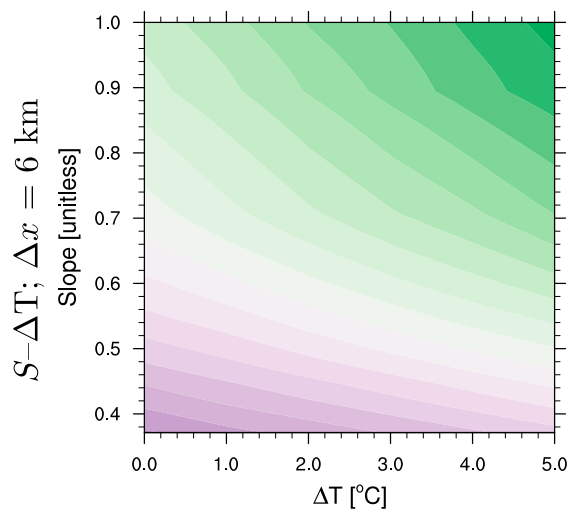

$w_{\max }\left[\mathrm{m} \mathrm{s}^{-1}\right]$

FIG. 7. As in Fig. 5, but assuming an instantaneous warming at a temperature of $-4^{\circ} \mathrm{C}$.

over $5 \mathrm{~km}$; Lebo and Morrison 2014) and that changes in aerosol loading may have a nonnegligible effect on cold pool intensity, which can affect $S$ (e.g., Rotunno et al. 1988; Lebo and Morrison 2014). At $-15^{\circ} \mathrm{C}$, which is far more reasonable for freezing in clouds, the required change in $S$ is cut in half relative to that at $-4^{\circ} \mathrm{C}$. These changes in $S$ are not only quite small relative to typical 0-6-km bulk shear in the atmosphere but also on par with observational errors in operational soundings (e.g., NWS 2010). Moreover, the link between changes in $S$ and cold pool intensity (which can also be modified as a result of changes in aerosol loading) indicates that aerosol effects on cold pools could be more substantial than aerosol effects on heating aloft, which was noted in Lebo (2014).

\section{b. Regressions}

To evaluate the relative importance of each variable on $w_{\max }$ across the entire parameter space, a linear regression analysis is performed on the suite of simulations for each case to estimate $w_{\max }$. Nonlinear regressions are also performed, including exponential and logarithmic functions; however, little improvement is found in the coefficient of determination $R^{2}$ (all of which exceed $0.88)$. The linear regressions are performed for each sounding and for warming placed at $10^{\circ}, 4^{\circ},-4^{\circ},-15^{\circ}$, and $-35^{\circ} \mathrm{C}$. To better estimate the importance of each parameter in determining $w_{\max }$, the variables are normalized by subtracting the mean and dividing by the standard deviation.

The resulting coefficients, denoted as $\beta_{\Delta T}, \beta_{S}$, and $\beta_{\Delta x}$ for the effects of warming, changes in slope, and changes in updraft width, respectively, are shown in Figs. 9 and 10 for the adiabatic and subadiabatic cases, respectively. The regression analysis is performed for different sets of $\Delta T$ owing to the fact that the actual range of possible $\Delta T$ is largely unknown observationally and can only be constrained by more sophisticated modeling. As discussed 


\section{Parameter Spaces for Warming at $-15^{\circ} \mathrm{C}$}

OK Squall Line
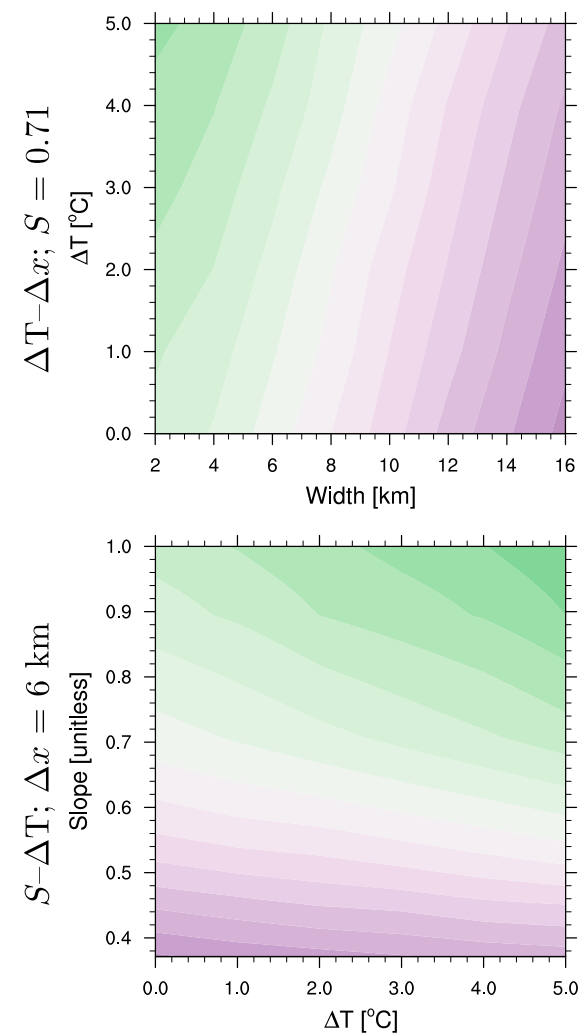

Tropical Cyclone
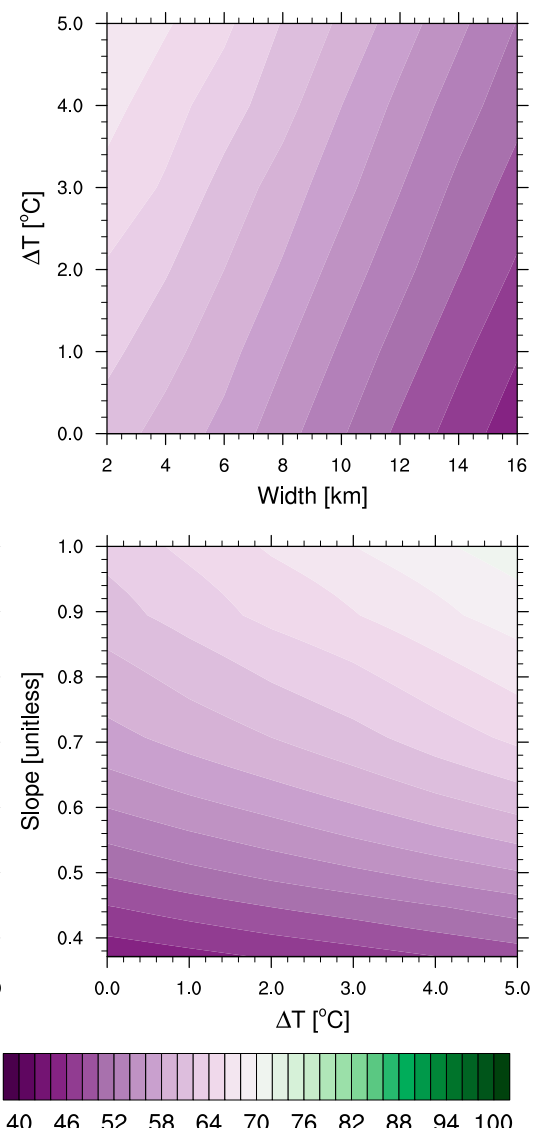

$w_{\max }\left[\mathrm{m} \mathrm{s}^{-1}\right]$

$\begin{array}{lllllllllll}40 & 46 & 52 & 58 & 64 & 70 & 76 & 82 & 88 & 94 & 100\end{array}$
Weisman and Klemp (1982)
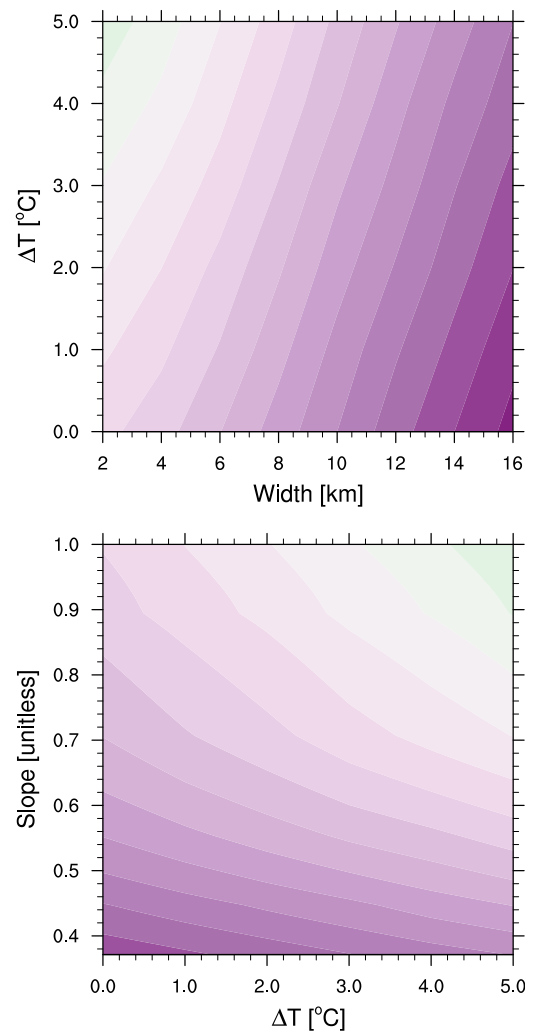

$$
w_{\max }\left[\mathrm{m} \mathrm{s}^{-1}\right]
$$

FIG. 8. As in Fig. 5, but assuming an instantaneous warming at a temperature of $-15^{\circ} \mathrm{C}$.

previously, such modeling work has largely suggested relatively small warmings; thus, the focus of the following analysis is largely placed on $\Delta T$ of no more than $1^{\circ}-2^{\circ} \mathrm{C}$ (e.g., Khain and Lynn 2009; Lee 2012; Herbener et al. 2014; Lebo 2014).

According to Fig. 9, the importance of $\Delta T$ clearly increases as the range of possible $\Delta T$ is expanded to larger values, increasing by nearly a factor of 3 for a range of $\Delta T$ from $0^{\circ}-1^{\circ}$ to $0^{\circ}-5^{\circ} \mathrm{C}$ (black to green), more or less regardless of the temperature at which the warming is applied (i.e., the relative change is insensitive to the chosen temperate, but the absolute change decreases as the warming is applied at lower temperatures). This conclusion is robust across the selected soundings. The other parameters (slope and width) exhibit far less sensitivity to the range of $\Delta T$ in the normalized regression analysis.

Comparing the coefficients in Fig. 9 suggests that in stronger convection, as denoted by the OK case, the importance of the imposed warming is minor compared to the updraft slope and width for small $\Delta T$ ranges. For example, for a range of $\Delta T$ of $0^{\circ}-1^{\circ} \mathrm{C}$ (black) in the $\mathrm{OK}$ scenario, $\beta_{\Delta T}$ is 3-4 times smaller than the coefficients for updraft slope and width for the highest temperature studied; the importance of the imposed warming diminishes as the warming is imposed at lower temperatures (i.e., higher in the cloud). In the slightly weaker cases (TC and WK), the importance of the imposed warming increases, although it is still smaller than for the updraft width and slope. Only once $\Delta T$ as large as $4^{\circ}-5^{\circ} \mathrm{C}$ (orange and green) applied at a temperature of $10^{\circ} \mathrm{C}$ is considered does the importance of the warming become comparable to the influence of updraft width and slope. For mixed-phase invigoration, even at an unrealistic freezing temperature of $-4^{\circ} \mathrm{C}$, no condition is sufficient for $\beta_{\Delta T}$ to be equivalent or greater than $\beta_{S}$ or $\beta_{\Delta x}$, indicating that the influence of warming above the freezing level via conventional invigoration 
OK Squall Line
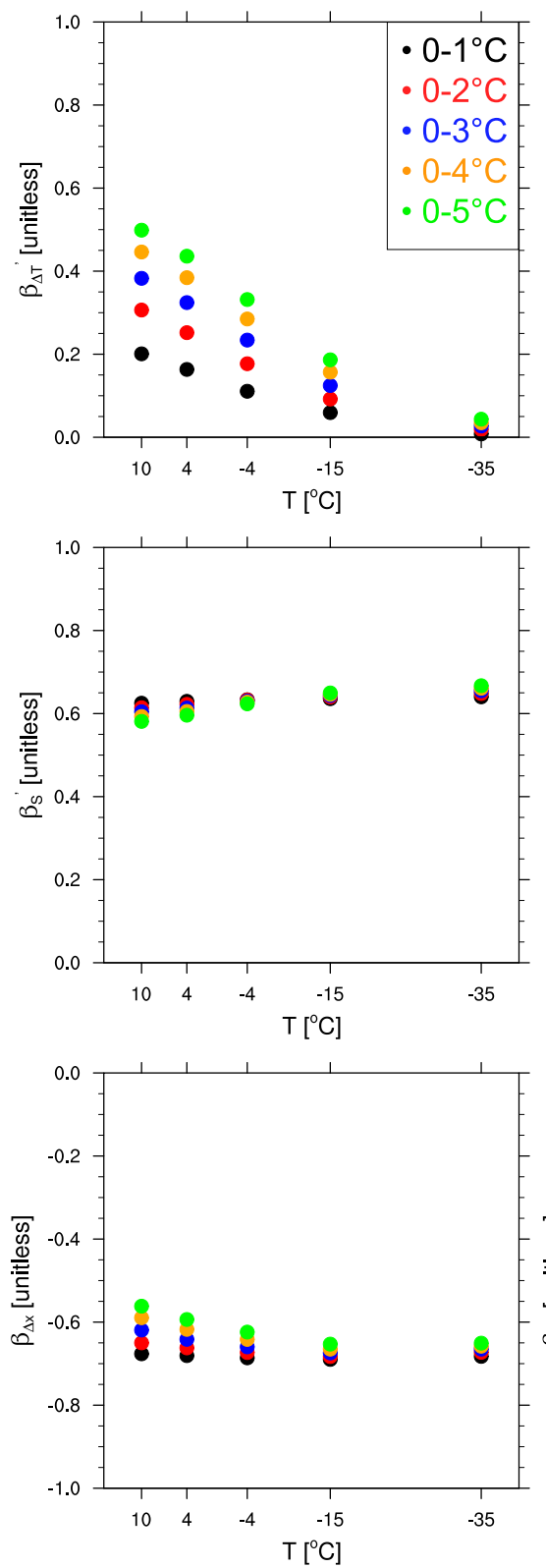

Tropical Cyclone
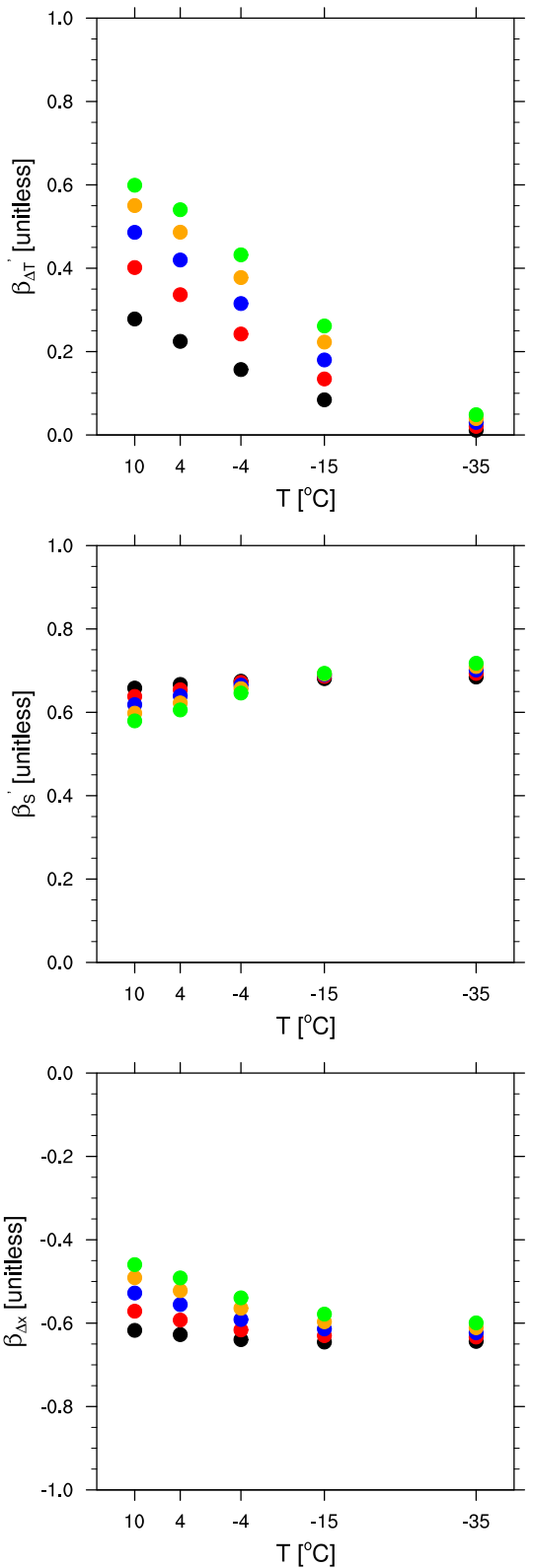

Weisman and Klemp (1982)
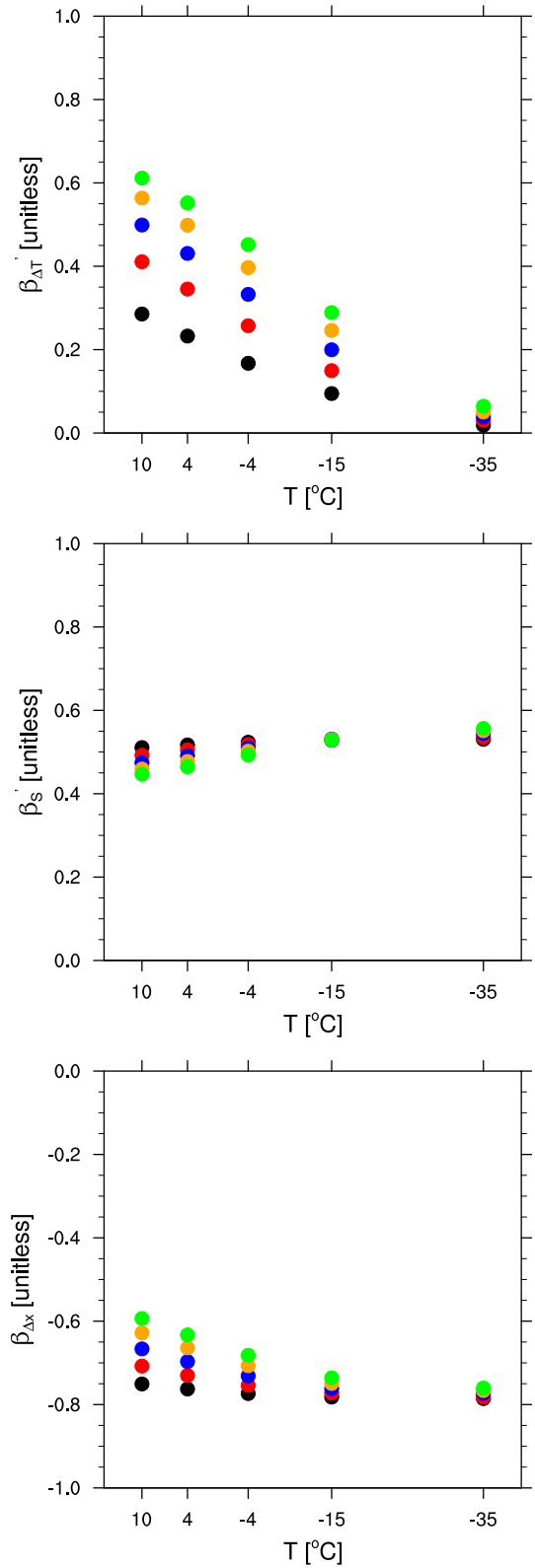

FIG. 9. Normalized regression coefficients (top) $\beta_{\Delta T}$, (middle) $\beta_{S}$, (bottom) $\beta_{\Delta x}$ as a function of the temperature at which the simulated warming is applied for the (left) $\mathrm{OK}$, (center) TC, and (right) WK soundings. Colors denote the range in $\Delta T$ used in the regression calculations: $0^{\circ}-1^{\circ}$ (black), $0^{\circ}-2^{\circ}$ (red), $0^{\circ}-3^{\circ}$ (blue), $0^{\circ}-4^{\circ}$ (orange), and $0^{\circ}-5^{\circ} \mathrm{C}$ (green).

arguments is very small in comparison to variability in updraft slope and width, which are both tightly coupled to changes in the environment, particularly wind shear. This analysis further emphasizes the results presented for the individual parameter spaces in section 3a because all parameters are simultaneously considered in the regressions.

A comparison between Figs. 9 and 10 indicates the impact of assuming adiabatic versus subadiabatic conditions, where the importance of warming increases under subadiabatic conditions, as denoted by an increase in $\beta_{\Delta T}$ for all soundings, $\Delta T$ ranges, and temperatures at which the warming is applied. As a result, under subadiabatic conditions, the warming may be as important as changes in updraft slope in terms of changes in $w_{\max }$ for small $\Delta T\left(0^{\circ}-2^{\circ} \mathrm{C}\right.$; black and red) applied at lower levels and more important for larger $\Delta T$ ranges (blue, orange, and green), 
OK Squall Line
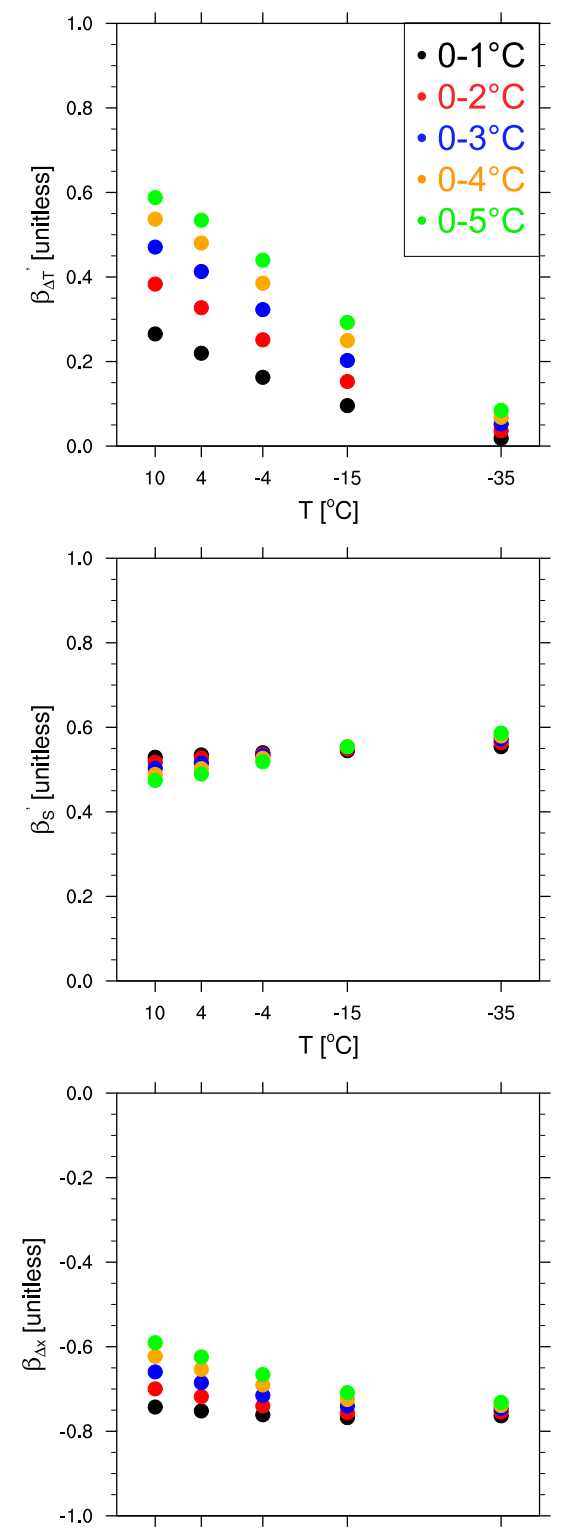

Tropical Cyclone
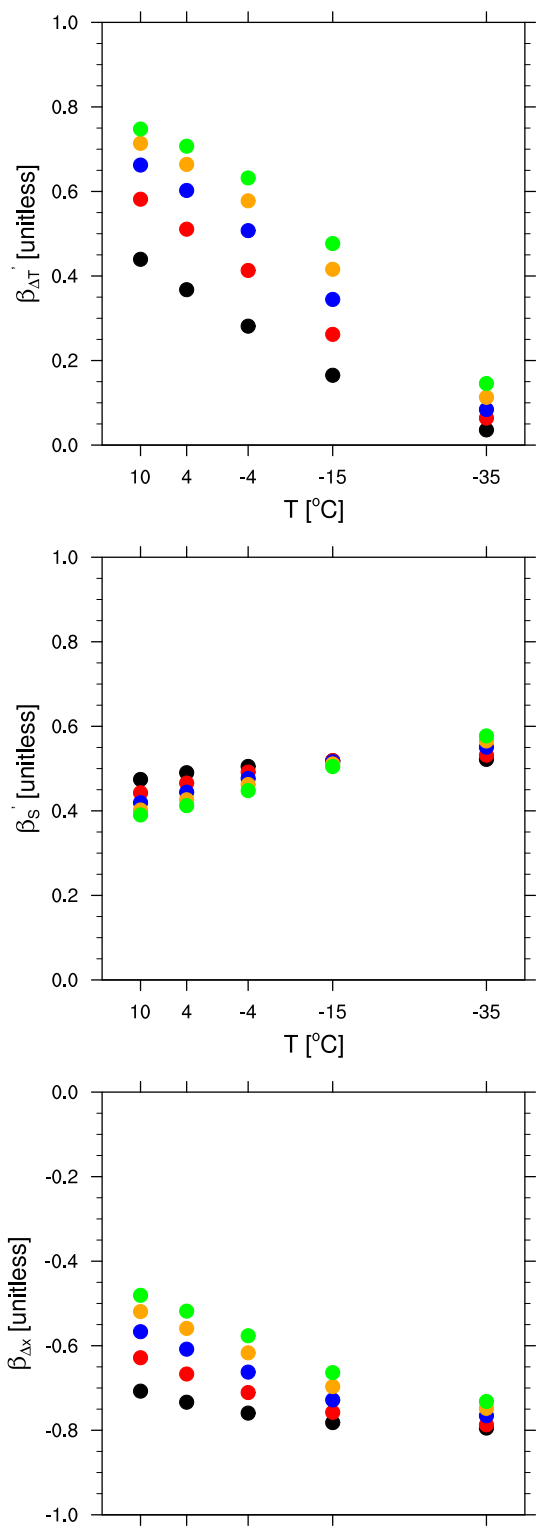

Weisman and Klemp (1982)
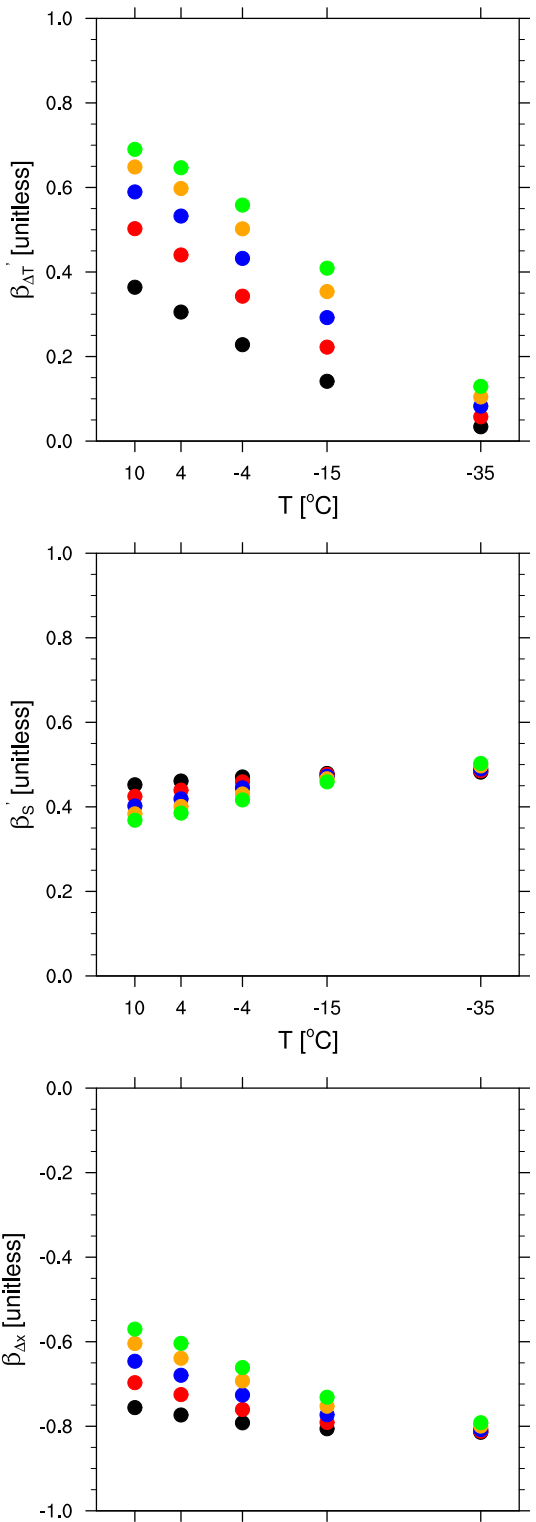

FIG. 10. As in Fig. 9, but for the subadiabatic soundings.

although, as discussed above, such warmings are unlikely based on prior modeling studies (e.g., Khain and Lynn 2009; Lee 2012; Herbener et al. 2014; Lebo 2014). In terms of changes in updraft width, warming only becomes as important or more important for the largest $\Delta T$ ranges (at least $0^{\circ}-3^{\circ} \mathrm{C}$; blue, orange, and green). For mixed-phase invigoration, except for the extreme $\Delta T$ ranges at $-4^{\circ} \mathrm{C}$, there is no scenario in which $\beta_{\Delta T}$ is as large or larger than $\beta_{S}$ or $\beta_{\Delta x}$. Thus, even in this more realistic scenario in which parcel ascent is assumed to be subadiabatic, invigoration effects due to aerosol-induced heating on updraft velocities are still expected to be quite small and difficult to distinguish from natural variability.

\section{Discussion}

In an attempt to aggregate the results of all simulations performed herein, we compute the probability of $\Delta w_{\max }$ exceeding certain thresholds $(15 \%, 10 \%$, and $5 \%$ ); these results are shown in Fig. 11 for warm (red) and mixed-phase (blue) invigoration in the adiabatic scenario. The $\Delta w_{\max }$ thresholds are set based on the mean and variability of $\Delta x$ found by Lebo and Morrison 

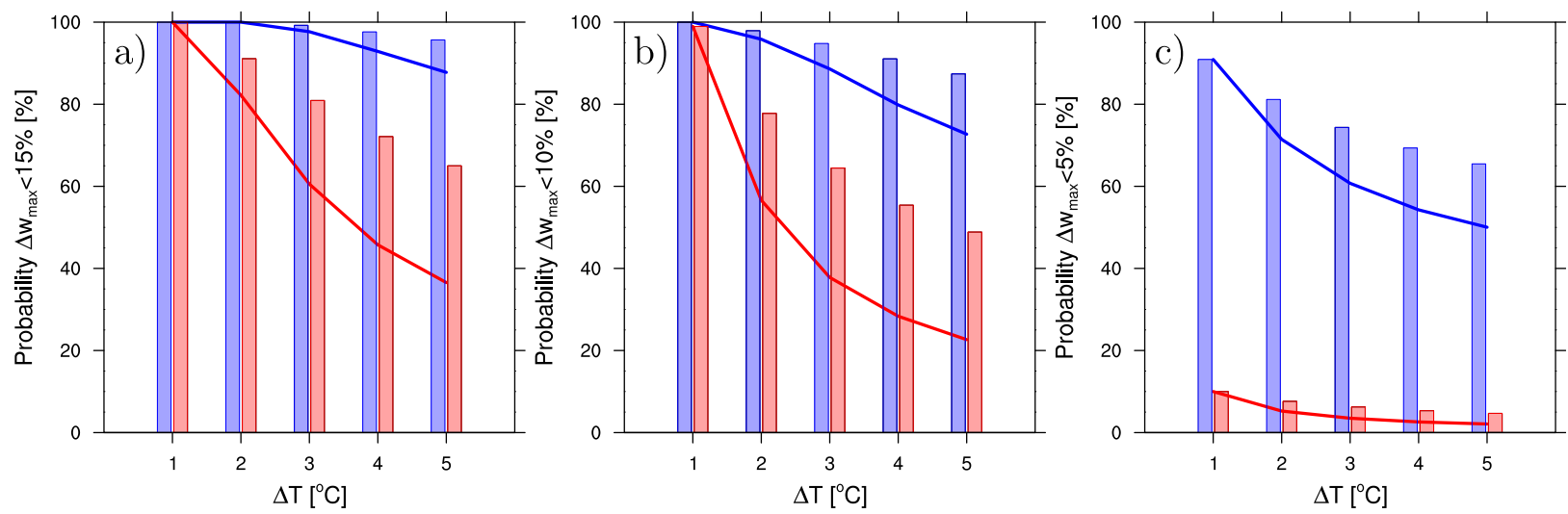

FIG. 11. Probability of $\Delta w_{\max }$ being less than (a) $15 \%$, (b) $10 \%$, and (c) $5 \%$; solid line shows the probability of exceeding the given $\Delta w_{\max }$ threshold for the $\Delta T$ denoted on the $x$ axis; the bars show the cumulative probability (i.e., average in this case) of all warmings less than or equal to the corresponding $\Delta T$ on the $x$ axis. The colors indicate invigoration in the warm (red) and mixed-phase (blue) regions.

(2015) and the resulting $\Delta w_{\max }$ shown in Fig. 4. For a normal distribution of $\Delta x$, two standard deviations from the mean (i.e., $6.0 \pm 2.5 \mathrm{~km}$ ) encompasses $95 \%$ of the possible values of $\Delta x$. According to Fig. 4 , for upright updrafts $(S=1)$, this range results in $\Delta w_{\max }$ of $\approx 15 \%$, whereas for highly sloped updrafts $(S=0.38)$, this $\Delta x$ range results in $\Delta w_{\max }$ of $\approx 5 \%$. Moreover, based on Lebo and Morrison (2014) and for $\Delta x$ of $6 \mathrm{~km}$, a change in shear by $0.7-1.8 \mathrm{~m} \mathrm{~s}^{-1}$ or $4 \mathrm{~m} \mathrm{~s}^{-1}$ over $5 \mathrm{~km}$ is needed for a $5 \%$ or $15 \%$ change in $w_{\max }$, respectively; these numbers do change for differences in $\Delta x$ around the mean, albeit slightly. As discussed in section 3, such changes in shear are quite small and even approach the limitations of observations due to data collection errors.

For completeness, the statistics for all $\Delta T$ are shown in Fig. 11; however, recall from section 1 that $\Delta T$ is expected to be $\leq 2^{\circ} \mathrm{C}$ based on a review of the relevant literature. Notably, $100 \%$ of all mixed-phase invigoration realizations for $\Delta T \leq 2^{\circ} \mathrm{C}$ result in $\Delta w_{\max }$ of $<15 \%$, and $98 \%$ result in $\Delta w_{\max }$ of $<10 \%$. For warm invigoration, these numbers decrease to $91 \%$ and $78 \%$, respectively, still representing the vast majority of the scenarios explored. Even when including all (even unrealistically large) $\Delta T$, the probabilities are still rather high, namely, $96 \%$ and $87 \%$ for mixed-phase invigoration and $65 \%$ and $49 \%$ for warm invigoration. Moreover, for realistic $\Delta T\left(\leq 2^{\circ} \mathrm{C}\right)$ and mixed-phase invigoration, $81 \%$ of the cases exhibit $\Delta w_{\max }<5 \%$. This again is only significant compared to changes in $\Delta x$ for the most tilted updrafts or very small changes in shear. When considering all $\Delta T, 65 \%$ of all realizations explored herein still produce $\Delta w_{\max }<5 \%$ for mixed-phase invigoration.

Figure 12 shows the aggregated results for the subadiabatic set of simulations. The results of the subadiabatic realizations are similar to the adiabatic case discussed above except that the percentages are lower. The differences between the adiabatic and subadiabatic scenarios are smallest for mixed-phase invigoration with realistic $\Delta T$ and $\Delta w_{\max }$ thresholds of $15 \%$ and $10 \%$. For
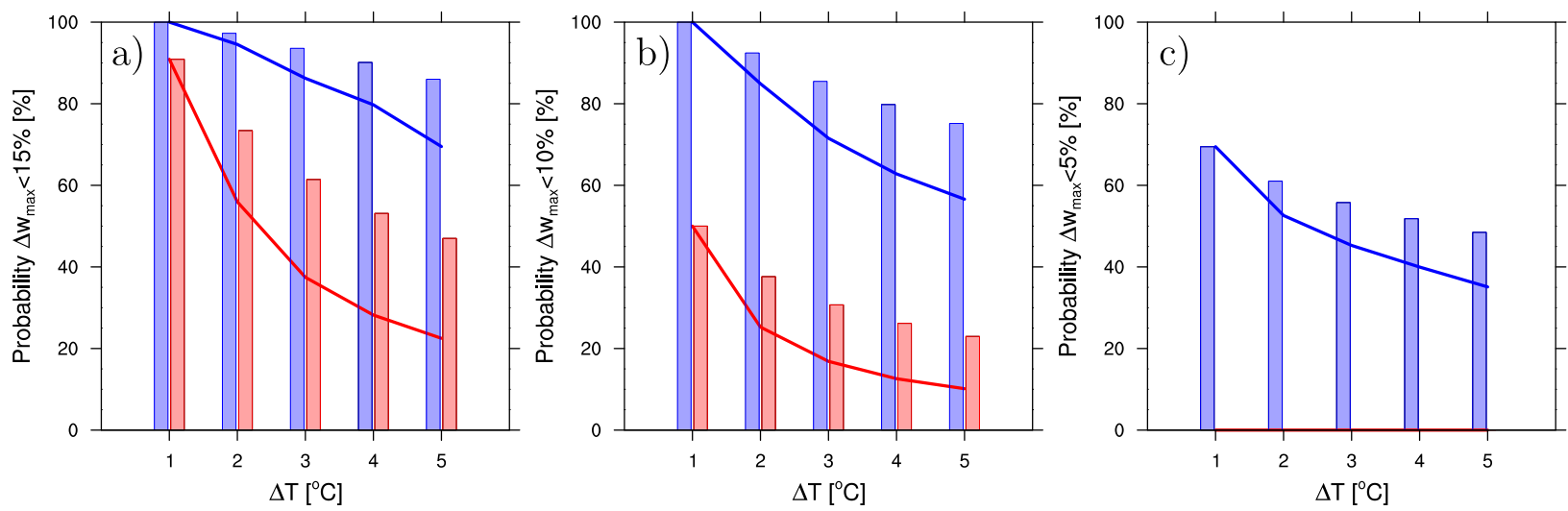

FIG. 12. As in Fig. 11, but for the subadiabatic simulations. 
the subadiabatic results, $97 \%$ and $92 \%$ of all mixedphase invigoration realizations for realistic $\Delta T\left(\leq 2^{\circ} \mathrm{C}\right)$ result in $\Delta w_{\max }$ of $<15 \%$ and $<10 \%$, respectively, which still represents the vast majority of the simulations performed herein. For warm invigoration and the smallest $\Delta w_{\max }$ threshold (5\%), all simulations result in $\Delta w_{\max }>5 \%$, although this is only significant for a small portion of the $S-\Delta x$ parameter space, namely, highly sloped and relatively wide updrafts (refer to Fig. 4 and section 3a). However, such wide updrafts exceed those expected from high-resolution modeling studies (e.g., Lebo and Morrison 2015), thus further limiting the potential to observe the effect of warming.

Furthermore, combining the warm and mixed-phase invigoration effects for realistic $\Delta T\left(\leq 2^{\circ} \mathrm{C}\right), 87.7 \%$ and $96.4 \%$ of the realizations result in $<15 \%$ change in $w_{\max }$ under subadiabatic and adiabatic conditions, respectively. For a stricter $\Delta w_{\max }$ threshold of $10 \%$, the percentage decreases slightly, decreasing further for the strictest $\Delta w_{\max }$ threshold value of $5 \%$; however, this latter case is only applicable for a very small (and arguably less realistic) portion of the $S-\Delta x$ parameter space. These aggregated results of all realizations provide a qualitative depiction of the relative impact of warming on $\Delta w_{\max }$ in the context of changes in $\Delta x$ and $S$, supporting the notion that observations of the effect will be highly challenging at best.

\section{Conclusions}

An idealized approach is presented that estimates changes in $w_{\max }$ due to changes in $S$ (updraft slope), $\Delta x$ (updraft width), and $\Delta T$ (warming associated with incloud phase changes to examine both the warm and mixed-phase invigoration hypotheses) for three wellstudied soundings. Both adiabatic and subadiabatic scenarios are explored. Hydrometeor loading of all condensate (i.e., liquid and ice) is neglected, meaning that the results presented herein serve as upper limits to changes in $w_{\max }$; this is especially true for the $w_{\max }$ response to $\Delta T$ because this warming is a direct result of additional freezing, deposition, and/or condensation, meaning that added condensate must be present. In reality, this condensate provides a negative buoyancy contribution that opposes the effects of the warming. This would ultimately limit the increases in $w_{\max }$ presented in Fig. 2 and the regression coefficient $\beta_{\Delta T}$ in Figs. 9 and 10. Even with this limitation, the results highlight several key findings:

(i) Warming below the freezing level (warm invigoration) is found to have a substantially larger effect on $w_{\max }$ than warming above the freezing level (mixed-phase invigoration) - as large as a factor of 2-3 higher at a temperature of $10^{\circ} \mathrm{C}$ compared with $-15^{\circ} \mathrm{C}$.

(ii) The magnitudes of both warm and mixed-phase invigoration are dependent on the thermodynamic sounding.

(iii) Buoyancy pressure perturbation effects can limit the increase in $w_{\max }$ relative to simple thermodynamic arguments by as much as a factor of 2 .

(iv) The $S-\Delta x$ parameter space is complex. Changes in $S$ have a small effects on $w_{\max }$ compared to changes in $\Delta x$ for nearly upright updrafts. The effects of changes in $S$ are maximized for sloped updrafts. The results presented herein demonstrate the complexity of the $S-\Delta x$ parameter space, which is important for future studies examining a single component of this space.

(v) In the context of the $S-\Delta T$ parameter space, $\Delta T$ has a larger effect for upright updrafts and warming located at higher temperatures, with the effect nearly diminishing for sloped updrafts and warming located in the mixed-phase region of the cloud, further highlighting the potential dominance of warm invigoration over mixed-phase invigoration.

(vi) Using guidance from previously published highresolution simulations of deep convective clouds, for warming located at $10^{\circ} \mathrm{C}, \Delta T$ would have to exceed approximately $1^{\circ} \mathrm{C}$ to have a larger effect on $w_{\max }$ than the natural variability in $\Delta x$. This increases to more than $2^{\circ} \mathrm{C}$ for warming located at $-15^{\circ} \mathrm{C}$.

(vii) Given the relatively small warming expected based on a review of the literature, detecting this effect in nature seems quite challenging because the natural variability in updraft width is likely to overwhelm changes in $w_{\max }$. Moreover, it is speculated that aerosol effects on cold pool intensity, which can affect $S$, could be more profound than even large $\Delta T$ aloft; future studies should address this issue using more complex numerical models.

(viii) For $\Delta T$ of $\leq 2^{\circ} \mathrm{C}, 87.7 \%$ and $96.4 \%$ of the realizations result in less than a $15 \%$ change in $w_{\max }$ under subadiabatic and adiabatic conditions, respectively, with only slight decreases for a lower $\Delta w_{\max }$ threshold of $10 \%$; these relative changes in $w_{\max }$ cover a wide range of the expected change in $w_{\max }$ for realistic changes in $S$ and $\Delta x$, further highlighting the limited likelihood of observing the effect of aerosol-induced warming in deep convective clouds.

The findings of this study indicate that the hypothesized aerosol invigoration effect on updraft velocities in deep convective clouds caused by enhanced freezing and deposition of condensate aloft or increased condensation below the freezing level is small compared to the effects 
of natural variability in environmental parameters that control updraft width and slope. This effect is strongest for aerosol-induced increases in condensation at low levels (i.e., warm invigoration) albeit still small in comparison to the effects of updraft slope and width on updraft velocities for the vast majority of the realizations based on a detailed normalized linear regression analysis of the complete and relevant parameter space and the aggregated statistics. The results corroborate and expand upon prior works that suggested a similar conclusion except over a limited region of the relevant parameter space and for an individual deep convective system (e.g., Storer et al. 2010; Fan et al. 2009; Lebo and Morrison 2014). To observe invigoration in any sense of the term, careful consideration of the spatial variability of the environment is warranted given that very small changes in shear and/or CAPE can have very large impacts on $w_{\max }$, overwhelming the expected change in $w_{\max }$ due to aerosol-induced warming alone; otherwise, it may be impossible to detect with any degree of confidence. Future work should focus on better constraining the natural spatial variability of the relevant environmental parameters to better quantify the probability of observing warm or mixed-phase invigoration.

Acknowledgments. The author thanks H. Morrison and M. Kumjian for their thoughtful comments and discussions relevant to this study and NCAR's Computational and Information Systems Laboratory for providing the MUDPACK library containing the Poisson solver. Special thanks go to Tarragon and Cilantro for their continued support.

\section{REFERENCES}

Adams, J. C., 1999: MUDPACK: Multigrid software for elliptic partial differential equations. NCAR, https://www2.cisl.ucar.edu/ resources/legacy/mudpack.

Berg, W., T. L'Ecuyer, and S. van den Heever, 2008: Evidence for the impact of aerosols on the onset and microphysical properties of rainfall from a combination of satellite observations and cloud-resolving model simulations. J. Geophys. Res., 113, D14S23, https://doi.org/10.1029/2007JD009649.

Boudala, F. S., G. A. Isaax, S. G. Cober, and Q. Fu, 2004: Liquid fraction in stratiform mixed-phase clouds from in situ observations. Quart. J. Roy. Meteor. Soc., 130, 2919-2931, https://doi.org/10.1256/qi.03.153.

Dennis, E. J., and M. R. Kumjian, 2017: The impact of vertical wind shear on hail growth in simulated supercells. J. Atmos. Sci., 74, 641-663, https://doi.org/10.1175/JAS-D-16-0066.1.

Doswell, C. A., and P. M. Markowski, 2004: Is buoyancy a relative quantity? Mon. Wea. Rev., 132, 853-863, https://doi.org/ 10.1175/1520-0493(2004)132<0853:IBARQ>2.0.CO;2.

Ekman, A. M. L., A. Engstrom, and A. Soderberg, 2011: Impact of twoway aerosol-cloud interaction and changes in aerosol size distribution on simulated aerosol-induced deep convective cloud sensitivity. J. Atmos. Sci., 68, 685-697, https://doi.org/10.1175/2010JAS3651.1.

Fan, J., and Coauthors, 2009: Dominant role by vertical wind shear in regulating aerosol effects on deep convective clouds. J. Geophys. Res., 114, D22206, https://doi.org/ 10.1029/2009JD012352.

Freud, E., and D. Rosenfeld, 2012: Linear relation between convective cloud drop number concentration and depth for rain initiation. J. Geophys. Res., 117, D02207, https://doi.org/10.1029/ 2011JD016457.

Grabowski, W. W., 2006: Indirect impact of atmospheric aerosol in idealized simulations of convective-radiative quasi equilibrium J. Climate, 19, 4664-4682, https://doi.org/10.1175/JCLI3857.1.

_ 2015: Untangling microphysical impacts on deep convection applying a novel modeling methodology. J. Atmos. Sci., 72 , 2446-2464, https://doi.org/10.1175/JAS-D-14-0307.1.

Heiblum, R. H., I. Koren, and O. Altaratz, 2012: New evidence of cloud invigoration from TRMM measurements of rain center of gravity. Geophys. Res. Lett., 39, L08803, https://doi.org/ 10.1029/2012GL051158.

Herbener, S. R., S. C. van den Heever, G. G. Carrio, S. M. Saleeby, and W. R. Cotton, 2014: Aerosol indirect effects on idealized tropical cyclone dynamics. J. Atmos. Sci., 71, 2040-2055, https://doi.org/10.1175/JAS-D-13-0202.1.

Hernandez-Deckers, D., and S. C. Sherwood, 2016: A numerical investigation of cumulus thermals. J. Atmos. Sci., 73, 41174136, https://doi.org/10.1175/JAS-D-15-0385.1.

Holton, J. R., 1973: A one-dimensional cumulus model including pressure perturbations. Mon. Wea. Rev., 101, 201-205, https:// doi.org/10.1175/1520-0493(1973)101<0201:AOCMIP>2.3.CO;2.

Jakob, C., and A. P. Siebesma, 2003: A new subcloud model for massflux convection schemes: Influence on triggering, updraft properties, and model climate. Mon. Wea. Rev., 131, 2765-2778, https:// doi.org/10.1175/1520-0493(2003)131<2765:ANSMFM >2.0.CO;2.

Jeevanjee, N., and D. M. Romps, 2016: Effective buoyancy at the surface and aloft. Quart. J. Roy. Meteor. Soc., 142, 811-820, https://doi.org/10.1002/qj.2683.

Jordan, C. L., 1958: Mean soundings for the West Indies area. J. Meteor. 15, 91-97, https://doi.org/10.1175/1520-0469(1958)015<0091: MSFTWI $>2.0 . \mathrm{CO} ; 2$.

Kanitz, T., P. Seifert, A. Ansmann, R. Engelmann, D. Althausen, C. Casiccia, and E. G. Rohwer, 2011: Contrasting the impact of aerosols at northern and southern midlatitudes on heterogeneous ice formation. Geophys. Res. Lett., 38, L17802, https:// doi.org/10.1029/2011GL048532.

Khain, A., and B. Lynn, 2009: Simulation of a supercell storm in clean and dirty atmosphere using Weather Research and Forecast Model with spectral bin microphysics. J. Geophys. Res., 114, D19209, https://doi.org/10.1029/2009JD011827.

- A. Pokrovsky, M. Pinsky, A. Seifert, and V. Phillips, 2004: Simulation of effects of atmospheric aerosols on deep turbulent convective clouds using a spectral microphysics mixed-phase cumulus cloud model. Part I: Model description and possible applications. J. Atmos. Sci., 61, 2963-2982, https://doi.org/ 10.1175/JAS-3350.1.

Klemp, J. B., 1987: Dynamics of tornadic thunderstorms. Annu. Rev. Fluid Mech., 19, 369-402, https://doi.org/10.1146/ annurev.fl.19.010187.002101.

Koren, I., J. V. Martins, L. A. Remer, and H. Afargan, 2008: Smoke invigoration versus inhibition of clouds over the Amazon. Science, 321, 946-949, https://doi.org/10.1126/science.1159185.

_ L. A. Remer, O. Altaratz, J. V. Martins, and A. Davidi, 2010: Aerosol-induced changes of convective cloud anvils produce climate warming. Atmos. Chem. Phys., 10, 5001-5010, https:// doi.org/10.5194/acp-10-5001-2010.

Kumjian, M. R., S. M. Ganson, and A. V. Ryzhkov, 2012: Raindrop freezing in deep convective updrafts: A microphysical and 
polarimetric model. J. Atmos. Sci., 69, 3471-3490, https://doi.org/ 10.1175/JAS-D-12-067.1.

Lebo, Z. J., 2014: The sensitivity of a numerically simulated idealized squall line to the vertical distribution of aerosols. J. Atmos. Sci. 71, 4581-4596, https://doi.org/10.1175/JAS-D-14-0068.1.

_ turbations on simulated idealized squall lines. Mon. Wea. Rev., 142, 991-1009, https://doi.org/10.1175/MWR-D-13-00156.1.

_ and _ 2015: Effects of horizontal and vertical grid spacing on mixing in simulated squall lines and implications for convective strength and structure. Mon. Wea. Rev., 143, 43554375, https://doi.org/10.1175/MWR-D-15-0154.1.

,-- , and J. H. Seinfeld, 2012: Are simulated aerosol-induced effects on deep convective clouds strongly dependent on saturation adjustment? Atmos. Chem. Phys., 12, 9941-9964, https:// doi.org/10.5194/acp-12-9941-2012.

Lee, S. S., 2012: Effect of aerosol on circulations and precipitation in deep convective clouds. J. Atmos. Sci., 69, 1957-1974, https:// doi.org/10.1175/JAS-D-11-0111.1.

— L. L. J. Donner, V. T. J. Phillips, and Y. Ming, 2008: Examination of aerosol effects on precipitation in deep convective clouds during the 1997 ARM summer experiment. Quart. J. Roy. Meteor. Soc., 134, 1201-1220, https://doi.org/10.1002/qj.287.

Li, Z., F. Niu, J. Fan, Y. Liu, D. Rosenfeld, and Y. Ding, 2011: Long-term impacts of aerosols on the vertical development of clouds and precipitation. Nat. Geosci., 4, 888-894, https://doi.org/ 10.1038/ngeo1313.

Markowski, P., and Y. Richardson, 2010: Mesoscale Meteorology in Midlatitudes. 1st ed. Wiley, $430 \mathrm{pp}$.

Morrison, H., 2016a: Impacts of updraft size and dimensionality on the perturbation pressure and vertical velocity in cumulus convection. Part I: Simple, generalized analytic solutions. J. Atmos. Sci., 73, 1441-1454, https://doi.org/10.1175/JAS-D-15-0040.1.

_ 2016b: Impacts of updraft size and dimensionality on the perturbation pressure and vertical velocity in cumulus convection. Part II: Comparison of theoretical and numerical solutions and fully dynamical simulations. J. Atmos. Sci., 73, 1455-1480, https://doi.org/10.1175/JAS-D-15-0041.1.

_ 2017: An analytic description of the structure and evolution of growing deep cumulus updrafts. J. Atmos. Sci., 74, 809-834, https://doi.org/10.1175/JAS-D-16-0234.1.

Murray, B. J., D. O'Sullivan, J. D. Atkinson, and M. E. Webb, 2012: Ice nucleation by particles immersed in supercooled cloud droplets. Chem. Soc. Rev., 41, 6519-6554, https://doi.org/ 10.1039/c2cs35200a.

NWS, 2010: Rawinsonde observations. NWS Tech. Rep. 10-1401, 208 pp.

Parker, M. D., 2010: Relationship between system slope and updraft intensity in squall lines. Mon. Wea. Rev., 138, 3572-3578, https://doi.org/10.1175/2010MWR3441.1.

_ , and R. H. Johnson, 2004: Structures and dynamics of quasi-2D mesoscale convective systems. J. Atmos. Sci., 61, 545-567, https:// doi.org/10.1175/1520-0469(2004)061<0545:SADOQM>2.0.CO;2.

Peters, J. M., 2016: The impact of effective buoyancy and dynamic pressure forcing on vertical velocities within two-dimensional updrafts. J. Atmos. Sci., 73, 4531-4551, https://doi.org/10.1175/ JAS-D-16-0016.1.

Phillips, V. J., A. Khain, N. Benmoshe, and E. Ilotoviz, 2014: Theory of time-dependent freezing. Part I: Description of scheme for wet growth of hail. J. Atmos. Sci., 71, 4527-4557, https://doi.org/10.1175/JAS-D-13-0375.1.

,,,--- , and A. Ryzhkov, 2015: Theory of timedependent freezing. Part II: Scheme for freezing raindrops and simulations by a cloud model with spectral bin microphysics. J. Atmos. Sci., 72, 262-286, https://doi.org/10.1175/JAS-D-13-0376.1.

Pruppacher, H. R., and J. D. Klett, 1997: Microphysics of Clouds and Precipitation. 2nd ed. Springer, $954 \mathrm{pp}$.

Rasmussen, E. N., and D. O. Blanchard, 1998: A baseline climatology of sounding-derived supercell and tornado forecast parameters. Wea. Forecasting, 13, 1148-1164, https://doi.org/ 10.1175/1520-0434(1998)013<1148:ABCOSD > 2.0.CO;2.

Romps, D. M., 2016: The stochastic parcel model: A deterministic parameterization of stochastically entraining convection. J. Adv. Model. Earth Syst., 8, 319-344, https://doi.org/10.1002/ $2015 \mathrm{MS} 000537$.

, and A. B. Charn, 2015: Sticky thermals: Evidence for a dominant balance between buoyancy and drag in cloud updrafts. J. Atmos. Sci., 72, 2890-2901, https://doi.org/10.1175/JAS-D-15-0042.1.

Rosenfeld, D., and W. L. Woodley, 2000: Deep convective clouds with sustained supercooled liquid water down to $-37.5^{\circ} \mathrm{C}$. Nature, 405, 440-442, https://doi.org/10.1038/35013030.

—, U. Lohmann, G. B. Raga, C. D. O'Dowd, M. Kulmala, S. Fuzzi, A. Reissel, and M. O. Andreae, 2008: Flood or drought: How do aerosols affect precipitation? Science, 321, 1309-1313, https://doi.org/10.1126/science.1160606.

Rotunno, R., J. B. Klemp, and M. L. Weisman, 1988: A theory for strong, long-lived squall lines. J. Atmos. Sci., 45, 463-485, https:// doi.org/10.1175/1520-0469(1988)045<0463:ATFSLL>2.0.CO;2.

Seifert, A., C. Köhler, and K. D. Beheng, 2012: Aerosol-cloudprecipitation effects over Germany as simulated by a convectivescale numerical weather prediction model. Atmos. Chem. Phys., 12, 709-725, https://doi.org/10.5194/acp-12-709-2012.

Seigel, R. B., S. C. van den Heever, and S. Saleeby, 2013: Mineral dust indirect effects and cloud radiative feedbacks of a simulated idealized nocturnal squall line. Atmos. Chem. Phys., 13, 4467-4485, https://doi.org/10.5194/acp-13-4467-2013.

Sheffield, A. M., S. M. Saleeby, and S. C. van den Heever, 2015: Aerosol-induced mechanisms for cumulus congestus growth. J. Geophys. Res. Atmos., 120, 8941-8952, https://doi.org/10.1002/ 2015JD023743.

Sherwood, S. C., D. Hernandez-Deckers, M. Colin, and F. Robinson, 2013: Slippery thermals and the cumulus entrainment paradox. J. Atmos. Sci., 70, 2426-2442, https://doi.org/10.1175/JAS-D-12-0220.1.

Storer, R. L., S. C. van den Heever, and G. L. Stephens, 2010: Modeling aerosol impacts on convective storms in different environments. J. Atmos. Sci., 67, 3904-3915, https://doi.org/10.1175/ 2010JAS3363.1.

Szeto, K. K., and H. R. Cho, 1994: A numerical investigation of squall lines. Part II: The mechanics of evolution. J. Atmos. Sci., 51, 425-433, https://doi.org/10.1175/1520-0469(1994)051<0425: ANIOSL $>2.0 . \mathrm{CO} ; 2$.

Tao, W.-K., X. Li, A. Khain, T. Matsui, S. Lang, and J. Simpson, 2007: Role of atmospheric aerosol concentration on deep convective precipitation: Cloud-resolving model simulations. J. Geophys. Res., 112, D24S18, https://doi.org/10.1029/2007JD008728.

Van den Heever, S. C., G. G. Carrio, W. R. Cotton, P. J. DeMott, and A. J. Prenni, 2006: Impacts of nucleating aerosol on Florida storms. Part I: Mesoscale simulations. J. Atmos. Sci., 63, 1752-1775, https://doi.org/10.1175/JAS3713.1.

Weisman, M. L., 1993: The genesis of severe, long-lived bow echoes. J. Atmos. Sci., 50, 645-670, https://doi.org/10.1175/ 1520-0469(1993)050<0645:TGOSLL $>2.0$. CO;2. , and J. B. Klemp, 1982: The dependence of numerically simulated convective storms on vertical wind shear and buoyancy. Mon. Wea. Rev., 110, 504-520, https://doi.org/ 10.1175/1520-0493(1982)110<0504:TDONSC > 2.0.CO;2. 
Wu, T., 2012: A mass-flux cumulus parameterization scheme for large-scale models: Description and test with observations. Climate Dyn., 38, 725-744, https://doi.org/10.1007/ s00382-011-0995-3.

Yuan, T., L. Remer, K. E. Pickering, and H. Yu, 2011: Observational evidence of aerosol enhancement of lightning activity and convective invigoration. Geophys. Res. Lett., 38, L04701, https://doi.org/10.1029/2010GL046052.
Zhang, G. J., 2009: Effects of entrainment on convective available potential energy and closure assumptions in convection parameterization. J. Geophys. Res., 114, D07109, https://doi.org/ 10.1029/2008JD010976.

Ziegler, C. L., E. R. Mansell, J. M. Straka, D. R. MacGorman, and D. W. Burgess, 2010: The impact of spatial variations of low-level stability on the life cycle of a simulated supercell storm. Mon. Wea. Rev., 138, 1738-1766, https://doi.org/10.1175/2009MWR3010.1. 